Discussion Papers in Economics

\title{
Gradualism in Aid and Reforms
}

Parimal Kanti Bag and Prabal Roy Chowdhury

February 2015

Discussion Paper 15-01

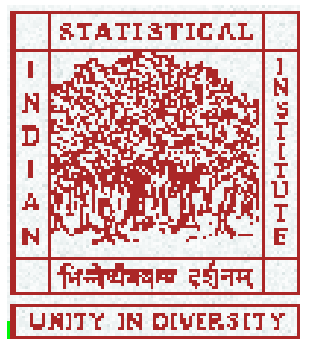

Indian Statistical Institute, Delhi

Economics and Planning Unit

7, S. J. S. Sansanwal Marg, New Delhi 110016, India 


\title{
Gradualism in Aid \& Reforms*
}

\author{
Parimal Kanti Bag ${ }^{\dagger} \quad$ Prabal Roy Chowdhury ${ }^{\ddagger}$
}

February 22, 2015

\begin{abstract}
The paper examines a problem of aid allocation by a donor country (or organization) to an LDC where aid diversion by the LDC bureaucrats/elite is a decreasing function of the level of governance. Irrespective of whether the donor can fully commit to a conditional aid program or not, it is shown that for maximal improvement in governance the aid should be disbursed in increments with each subsequent tranche being conditional on prior reforms, instead of resorting to a quick-fix solution (aid gradualism). While the attraction of future aid incentivizes the recipient bureaucrats to implement reforms, these reforms in turn also make aid diversion less feasible. Further, under full commitment, the optimal aid package may involve offering interim bribes to bureaucrats in an effort to ultimately improve governance and lower corruption. With only partial commitment (so that time consistency requires the donor to reconfigure aid in each round), it is shown that (a) interim bribery is no longer viable, and (b) both the aid and implemented reforms exhibit strong gradualism, or what is known as the starting small and grow later principle in commitment models.
\end{abstract}

JEL Classification: H8, O2.

Key Words: Budgetary cost of structural reforms, budgetary aid, aid diversion, bureaucrats, corruption, transparency, governance, time consistency, commitment, gradualism, start small grow later (SSGL) principle.

${ }^{*}$ Preliminary draft. Thanks to Neng Qian and Sayoudh Roy for their research assistance. Grants from the Singapore Ministry of Education are gratefully acknowledged.

${ }^{\dagger}$ Department of Economics, National University of Singapore, Faculty of Arts and Social Sciences, AS2 Level 6, 1 Arts Link, Singapore 117570; E-mail: ecsbpk@nus.edu.sg

${ }^{\ddagger}$ Economics and Planning Unit, Indian Statistical Institute, New Delhi, India; E-mail: prabalrc@isid.ac.in 


\section{Introduction}

As recently as January 2012, politicians in the UK were calling for imposition of conditions on foreign aid: "Aid given by the UK to countries with a history of fraud and corruption should be 'conditional' on them improving their governance, MPs have said." ${ }^{1}$ The UK Commons International Development Committee suggested that aid should be withdrawn if these conditions are not met. International Development Secretary, Andrew Mitchell, said: "We make absolutely clear to countries that transparency and good governance are vital. We are prepared to withhold funding to governments when our standards are not met, as we have done in Malawi." The UK, in fact, reduced aid to Malawi in 2011 amid concerns about extravagant spending by ministers and a government clampdown on human rights. In another major ongoing aid debate, regarding whether eurozone should extend the bailout to Greece, Gavin Hewitt writes in a BBC report (17 February, 2015): "The Germans believe that the bailout, with its austerity conditions, is the only way of ensuring that Greece sticks to reforms." (http://www.bbc.com/news/world-europe-31501777.)

The efficacy of aid is an oft-debated issue. While it has sometimes been argued that aid doesn't work, ${ }^{2}$ it has also been argued, equally often, that it does. A recent UNICEF report argues, for example, that global mortality rates of children fell over the last 20 years due to "well-targeted aid such as encouraging breastfeeding or immunizing against common diseases." 3 In this paper we seek to examine the reasons behind the success or failure of aid, arguing that aid design, in particular the kind of conditionality advocated in the recent debates in the UK, is a critical element in determining how effective a particular aid program is going to be.

Conditional aid has, of course, been widely used in reality. Around the millennium period, the World Bank routinely imposed conditionality on aid, requiring a long list of reforms in governance (see Santiso (2001a), Santiso (2001b), and Kapur and Webb (2000)). ${ }^{4}$ Temple (2010) (p. 4464) mentions the case of the Millennium Challenge Account, launched by the US Government in 2004, linking aid to political freedoms, control of corruption,

\footnotetext{
${ }^{1}$ Source: http://www.bbc.co.uk/news/uk-politics-16410677. This is also the source of the other quotes, as well as the information in this paragraph.

${ }^{2}$ See Svensson (2000a) and several references cited there, Boone (1996), Burnside and Dollar (2000), Svensson (2000b), Svensson (2003), Easterly (2003), Bourguignon and Sundberg (2007).

${ }^{3}$ This report report notes: "Sierra Leone in West Africa - one of the world's poorest nations - ranks among the top five countries seeing improvements in child mortality in the past decade. The others were Niger, Malawi and Liberia - also in Africa - and East Timor in South East Asia" (source: http://www.bbc.co.uk/news/world-19581433; http://www.bbc.co.uk/news/world-14930778).

${ }^{4}$ One also hears views by political leaders of powerful developed countries wanting a certain type of governance, in the name of democracy, to prevail in the LDCs.
} 
and respect for civil liberties and the rule of law. ${ }^{5,6}$ Why do aid programs often involve conditionality? To this end the literature has identified some problems intrinsic to nonconditional aid that may make conditionality useful. Banerjee and He (2008) argue, for example, that given the leakages in aid arising out of a lack of monitoring, transparency and governance, the provision of aid requires careful program evaluations that involve more than simply identifying the more deserving projects. ${ }^{7}$ Banerjee (2007) discusses alternative ways of enhancing the effectiveness of aid, including making governments compete for aid through transparency, as well as detailed micro management of targeted projects.

We analyze the issue of aid conditionality using a dynamic framework where the total aid amount can be disbursed over three periods, if so desired. Delivery of aid however involves an ex post moral hazard problem in that a part of the aid can be diverted by the privileged class, and may not reach the intended beneficiaries. The extent of such diversion depends on the level of governance, where governance can be broadly defined to include transparency (which includes free press), liberalization, fiscal stabilization, privatization and other such measures, so that with better governance less can be diverted. Thus the donor, who cares about governance, can condition the release of future tranches on governance improvement. Given that it has been argued that the lack of commitment is a key reason as to why aid programs may fail (see Kanbur (2000)), we consider two different scenarios, with different degrees of commitment by the donor. We first consider a full conditional commitment (or FCC) program, where the donor can commit to the aid program from the beginning. We also consider an alternative scenario where the donor cannot commit fully to the aid package over the entire three periods, but instead will have to solve for a partial conditional commitment (or PCC) program.

Before turning to the results we discuss certain aspects of our modelling strategy. First, why focus on governance? Governance improvements can be an objective in itself, as they

\footnotetext{
${ }^{5}$ Temple (2010) finds that the history of aid shows that governance was one of the focus in the 1990s and 2000s (see Table 1 on p. 4424).

${ }^{6}$ Interestingly such conditionality have been widely used in concessional credit programs as well. Conway (2003) argues that the concessional aid programs under IMF follow a similar pattern, "The credit available in an IMF arrangement is disbursed in tranches. The tranches are disbursed according to a set timetable on the request of the borrowing country. Later tranches can only be disbursed if the country has met the conditions defined in the Letter of Intent associated with the arrangement. Thus, if the country has not met the conditions, then only the first tranche will be disbursed." Further, he says that "Pakistan has a long history as a user of IMF credit facilities. This history can be broken into two parts: the initial generation (1958-1978) of non-cancelled and nearly completely disbursed arrangements, and a subsequent generation (1980-2000) of arrangements with limited disbursement and frequent cancellation."

${ }^{7}$ International aid agencies and governments are beginning to place a greater emphasis on transparency in deciding on aid. The Guardian, the UK newspaper, runs the headline - "Transparency will make aid work better: A global standard on sharing information is at the heart of democratizing aid - for donors and for recipients" (21 December, 2010 report at http://www.guardian.co.uk/global-development/povertymatters/2010/dec/21/aid-transparency-global-standard).
} 
promote the liberal values that the donors themselves treasure. Further such governance improvements have an instrumental purpose, in that reforms help in facilitating development. For example, while Kaufmann et al. (1999) documents empirical evidence of a strong causal relationship between governance and development, Svensson (1999) has argued that aid impacts positively on growth with better democracy (i.e., institutional check on governmental power). ${ }^{8}$

Second, one key feature of the analysis is to recognize that recipient countries are resource constrained. Hence aid plays a critical role in covering the costs of reforms, which can be either direct or indirect. As Bakoup (2013) argues, indirect costs may involve “... i) transfers either between the various socioeconomic categories or between the government and such socioeconomic categories; ii) government staffing expenditures; iii) tax expenditures; iv) net depreciation of non-tax revenues; v) public sector net lending; and vi) debt service variations." Also, for reforms spanning several fiscal years, the political feasibility of the needed funds transfer could be an issue, so that budgetary aid becomes relevant. ${ }^{9}$ This implies that holding back the entire aid and disbursing it only after the reforms have occurred is not feasible as it facilitates carrying out costly reforms along with implementing development programs.

Third, we consider a framework where reforms as well as the related costs can be verifiably measured. Temple (2010) (section 9.1 on aid conditionality, p. 4469) discusses how aid can be conditioned on reform efforts that can be verified directly, or indirectly, and how reforms might improve the welfare of the poor. Bakoup (2013) ${ }^{10}$ also suggests that the measurability issues are not insurmountable. He points out that in recent decades budgetary aid, aimed at offsetting the negative financial effects of reforms in the short to medium term, is becoming a significant component of European Union and African Development Bank (ADB) aid operations geared towards economic and structural reforms. ${ }^{11,12}$

We shall focus on two central issues. The first one is that of aid gradualism. Should aid

\footnotetext{
${ }^{8}$ In a related paper, Bag and Roy Chowdhury (2014), we study the problem of a donor maximizing the effective aid to the poor, i.e., their welfare. Such an objective can be termed as the developmental goal or warm-glow objective. There is some parallel in the two analysis with gradualism also featuring in the alternative formulation.

${ }^{9}$ The government's intertemporal budget may start from a negative balance during initial years of reform to a positive balance in subsequent years. See the discussion in Bakoup (2013).

${ }^{10}$ See also some of the related references there.

${ }^{11}$ The European Commission defines budget support as "policy dialogue, financial transfers to the national treasury account of the partner country, performance assessment and capacity building based on partnership and mutual accountability." See EC (2011). (source: Bakoup (2013).)

$1225 \%$ of European Union's 13 billion EURO external aid over the 2003-2009 period is budgetary aid; $31.3 \%$ of the 11.3 billion Units of Account of the operations of the ADB window and $21.8 \%$ of the 10.9 billion UC operations of the ADF windows respectively at the ADB over the period 1999-2009 (source: Bakoup (2013)).
} 
be staggered at all, with future tranches being dependent on past performance? Clearly any requirement that the recipient engages in costly reforms will go unheeded if the aid is given up front. So disbursing the aid over two rounds, with the second round being conditional on governance improvement, certainly seems to be a better alternative. But when it comes to extending this logic to more than two rounds, the issue is less clearcut.

One potential problem with extending this logic to more than two rounds is that of commitment. If the donor cannot commit to the aid program at the beginning, i.e. solves a PCC program rather than an FCC program, then such splitting up may not be time consistent, and hence not implementable. As to other potential issues with staggering aid over more than two periods, consider an aid scheme which is staggered over three periods, say. Note that transferring some of the aid amount from later rounds to an earlier round may allow the donor to provide greater incentives, as the recipient elite can appropriate a greater fraction of any aid amount early on, since the reforms are yet to fully kick in. This may not only allow for greater reforms early on, such reforms would relax the incentive constraints down the line, which may make eventual improvements in governance levels possible.

Our results are as follows. We find that irrespective of the commitment abilities, the optimal aid delivery mechanism involves gradualism, conditioning the continuation of future aid upon intermediate reforms. These results therefore address an important debate in the aid literature: transformation versus gradualism; see Temple (2010) (p. 4422). Given gradualism, a related question is the issue of starting slow versus a big bang approach. We find that in case full commitment is not possible, aid and reforms exhibit an increasing pattern, that is, start with small improvements and push for bigger gains in the later stages, thus conforming with the insights of conditional commitment models, e.g., Watson (2002), Klimenko et al. (2008). At this point we should emphasize that we allow for linear costs, which does not favor either gradualism, or starting small. Thus neither of these results can be traced to purely technological reasons.

A second issue of interest is that of interim bribery, i.e. whether to allow for excess aid at an intermediate stage, over and above that required to cover the costs of reforms so as to incentivize the elite to deliver on governance. Interestingly we find that such interim bribery may happen if the donors can fully commit to its aid program. The analysis suggests that (a) interim bribery is less likely under partial commitment, and (b) such interim bribery as a fraction of total aid increases as the volume of aid goes up. Hence if a likely change in leadership on the donor side means full commitment to future aid is no longer credible, then this weakens the potential effectiveness of aid.

Before proceeding to the formal model we briefly relate our paper to the literature. The role of gradualism has been examined in other economic applications, from dynamic 
prisoner's dilemma and contribution games (Marx and Matthews (1998), Lockwood and Thomas (2002), etc.) to international trade (Staiger (1995), Bond and Park (2002), Chisik (2003), etc.), diplomacy and bargaining. ${ }^{13}$

In the context of investment, Neher (1999) examines the role of staggered investment in solving the holdup problem facing a venture capitalist. Unlike Neher (1999) however, the present paper analyzes aid diversion, rather than holdup in investment. Further, in the present paper the donor solves a maximization problem, as opposed to designing an investment sequence for a fixed investment need. In the context of aid, Carter et al. (2015) analyze a problem involving multiple aid recipients where a single donor chooses an optimal dynamic aid plan to maximize a weighted sum of the recipient countries' welfare. The authors' main focus is on the effect of differential aid absorption ability of the recipients. Neither of these papers allow for aid diversion, nor do they address the issue of aid conditionality.

We start with the basic framework in the next section. In section 3 we analyze the simpler two period problem. The main results based on the analysis of a three period model is presented in section 4, and conclusions in section 5. The proofs are included in an Appendix. A supplementary file separate from this manuscript contains Mathematica simulations relating to Proposition 7.

\section{Basic Framework}

There are two players - a donor and an LDC. The donor has an aid budget $\mathcal{A}$ earmarked for a specific LDC. The purpose of this aid is to incentivize some target level of reform, aimed at improving governance in the LDC. Such an objective reflects a belief on the part of the donor that the lack of development in the LDC can essentially be attributed to a lack of governance - transparency, right institutions, efficient administration, among others - and once that is taken care of the donor country can fend for itself.

We assume that the magnitude of $\mathcal{A}$ has been already determined by internal considerations in the donor organization, and is thus exogenous to our problem. ${ }^{14}$ Once the magnitude

\footnotetext{
${ }^{13}$ In December 2011 the US Secretary of State Hillary Clinton pledged to improve ties with Burma on the condition of political reforms: "These are incremental steps and we are prepared to go further if reforms maintain momentum. In that spirit, we are discussing what it will take to upgrade diplomatic relations and exchange ambassadors." (See http://www.bbc.co.uk/news/world-asia-15978893.) Peace processes involving the Arab-Israeli conflict, the Northern Ireland conflict and the likes are prime examples of gradual approach with respect to compromises and concessions adopted by politicians and international bodies to reach agreements.

${ }^{14}$ The donor might be a rich country or an organization with international influence such as the World Bank, the IMF, the United Nations, or even a charity. Aid budget may be determined for a region first, then broken down for specific countries.
} 
of aid is decided, the donor simply wants to maximize its objective by disbursing the available budget. We assume that the donor has other usage of the fund to which it can transfer any unutilized aid amount, so that it can credibly commit to cancelling the aid program in case any aid conditionalities are not being adhered to. ${ }^{15}$ Further, the aid is of general nature in that it is not tied to any specific project, and it is up to the recipient country as to how it spends the grant.

The LDC is governed by an elite class who determine, in its own interests, whether some key reforms should take place or not. One can think of the elite class of comprising not just the bureaucrats, but also possibly politicians, influential businessmen, etc. The objective of the elite is to maximize aid diversion, i.e. the amount of aid money that it can appropriate. Thus in any period $t$, in case a surplus fund of $S$ is available, the elite can appropriate a fraction $\alpha\left(g_{t}\right)$ of this fund, where $g_{t}$ denotes the level of governance in the LDC at period $t$. The fraction of $S$ remaining after elite appropriation, $\left(1-\alpha\left(g_{t}\right)\right)$, is used for consumption by the poor (hospitals, schools, food and shelter to the flood affected victims, and the likes), which we call developmental benefits. Ascribing such uncharitable motives to the elite may not be too far from reality as evidenced by the experience of aid agencies dealing with the LDCs.

The level of governance may be thought of as simply the inverse of some corruption index. It's an aggregative summary of how a country is perceived by the outside world. Governance may be improved by passing better laws (including, in some instances, simplification in tax rules), tightening enforcement, bringing in more transparency, improving the freedom of the press, opening up the economy to competition, both domestic was well as foreign, etc. All of these ensure, directly or indirectly, that the public duties carried out by the government will be more efficient and less prone to corruption and undue influence. This also means that any development initiative undertaken with the help of international aid money will be less likely to be diverted.

Improving the level of governance from $\mathrm{g}$ to $\mathrm{g}^{\prime}$ involves a cost of $\mathrm{C}\left(\mathrm{g}^{\prime}-\mathrm{g}\right)$. While this cost can be interpreted as a purely technological one, arising out of the need to upgrade facilities and services (such as more record keeping of accounts, complaints, procedural scrutiny, committee works, etc.), we interpret it more broadly. In particular, this cost can be attributed to the necessary compensatory measures, including direct transfers, that the incumbent government must make to those who lose out from reforms (see Temple (2010), paragraph 2, section 9.1 on 'Policy conditionality', p. 4429). Replacing labor intensive bureaucracy by machines would incur direct costs and sometimes indirect costs due to resistance from trade

\footnotetext{
${ }^{15}$ We do not model credible commitment - an explicit modelling would require multiple recipients. See, for instance, Svensson (2003).
} 
unions; filling in the posts of vacant judges for better law enforcement is costly; and so on. These reforms must come at the expense of the government's alternative expenditure plans or it must be financed out of aid money. We will assume that the country in question is cash strapped, so that reforms become easier with external help. Further, reforms take one period to mature.

We shall maintain the following assumptions regarding $\alpha(\mathrm{g})$ and $\mathrm{C}($.$) :$

Assumption 1. (i) $\alpha(\mathrm{g})$ is strictly decreasing, and twice differentiable in $\mathbf{g}$.

(ii) $\mathrm{C}($.$) is strictly increasing, and weakly convex (thus twice differentiable), with \mathrm{C}(0)=0$.

Throughout we will assume that neither the donor nor the recipient discount the future. In the next section we begin by considering a two period model, followed by a three period model in section 4 .

\section{Two Period Horizon}

The LDC has an initial level of governance $g_{1}$ determined by its institutions, in particular rules and enforcement machinery. We take it that $g_{1} \geq \underline{g}$, where $\underline{g}>0$ is the minimal competence required for a functioning government. The donor is interested in maximizing the level of governance at the end of the planning horizon, denoted $g_{2}$ :

[Two Period Aid-governance program] Given a fixed aid budget $\mathcal{A}>0$, the donor provides an aid $\mathcal{A}_{1} \geq 0$ to the LDC at $\mathrm{t}=1$ asking it to engage in reforms so as to improve its governance level to $g_{2}$. At $t=2$, the donor provides a further aid of $\mathcal{A}_{2} \geq 0$ provided the governance level at $t=2$ is at least $g_{2}$. In case the governance level falls short of $g_{2}$, no further aid is provided. Hence

$$
\mathcal{A}_{1}+\mathcal{A}_{2}=\mathcal{A}
$$

The donor's problem. The donor country's problem is to design an appropriate aid program so as to maximize $\mathrm{g}_{2}$ subject to (a) the incentive constraint that the LDC does not default on $g_{2}$, and (b) the financial constraint that the available funds are sufficient to cover the costs of reforms. Further, the donor can commit to this conditional aid program, in that it cannot renege on its aid commitment of $\mathcal{A}_{2}$ in period 2 provided the governance improvement has been implemented. This is important since clearly part of the last-period aid, $\mathcal{A}_{2}$, will be diverted by the bureaucrats without generating any governance improvements. ${ }^{16}$

\footnotetext{
${ }^{16}$ In the next section we shall examine the implications of different degrees of commitment for the three period problem.
} 
The incentive compatibility constraint (in short, IC) facing the LDC elite at $t=1$ is given by:

$$
\alpha\left(\mathrm{g}_{1}\right)\left[\mathcal{A}_{1}-\mathrm{C}\left(\mathrm{g}_{2}-\mathrm{g}_{1}\right)\right]+\alpha\left(\mathrm{g}_{2}\right) \mathcal{A}_{2} \geq \alpha\left(\mathrm{g}_{1}\right) \mathcal{A}_{1},
$$

where the RHS denotes the immediate payoff to the elite if they decide to renege on the contract and appropriate the maximal possible payoff immediately, whereas the LHS is the sum of its payoff at $t=1$ in case it decides to invest in improving governance to $g_{2}$. Simplifying, we obtain:

$$
\frac{\alpha\left(g_{2}\right) \mathcal{A}_{2}}{\alpha\left(g_{1}\right)} \geq C\left(g_{2}-g_{1}\right)
$$

The LDC also faces a financial constraint (or FC) in that the aid available at $t=1$ must be enough to fund the suggested reforms:

$$
\mathcal{A}_{1} \geq \mathrm{C}\left(\mathrm{g}_{2}-\mathrm{g}_{1}\right)
$$

Definition 1. Given an aid budget of $\mathcal{A}>0$, an aid-governance program $\left(\tilde{\mathcal{A}}_{1}, \tilde{g}_{2} ; \tilde{\mathcal{A}}_{2}\right)$ will be referred to as a 2-round optimal program if it maximizes $\mathrm{g}_{2}$ subject to (1), (2) and (3).

We start with an observation on the ideal aid/governance program.

Lemma 1. The optimal aid-governance program must involve gradualism in the sense that (i) the donor spreads the aid over two periods, i.e. $\tilde{\mathcal{A}}_{1}>0, \tilde{\mathcal{A}}_{2}>0$, and (ii) the level of governance improves over time, i.e. $\tilde{\mathrm{g}}_{2}>\mathrm{g}_{1}$.

The result is intuitive, since either giving away the entire aid in the first round, or delaying all aid until the second, will achieve zero reform.

A more complete characterization of the optimal aid program can be presented as follows.

Proposition 1 (Two rounds better than one). In the optimal solution both the incentive constraint (2) and the financial constraint (3) must hold with equality, determining the maximum implementable governance, $\tilde{\mathrm{g}}_{2}>0$, uniquely. Further,

(i) In period 1, aid is completely reforms related in that it is just enough to cover the expenses towards governance improvement, i.e., $\tilde{\mathcal{A}}_{1}=\mathrm{C}\left(\tilde{\mathrm{g}}_{2}-\mathrm{g}_{1}\right)>0$.

(ii) The aid in period 2, $\tilde{\mathcal{A}}_{2}>0$, is not spent on governance improvement at all. Out of the aid $\tilde{\mathcal{A}}_{2}$, only $\left(1-\alpha\left(\tilde{\mathbf{g}}_{2}\right)\right) \tilde{\mathcal{A}}_{2}$ trickles down to the poor and $\alpha\left(\tilde{\mathbf{g}}_{2}\right) \tilde{\mathcal{A}}_{2}$ is diverted by the elite.

(iii) $\tilde{\mathcal{A}}_{2}>\tilde{\mathcal{A}}_{1}$, i.e., the donor must leave a greater share of the aid for future for bureaucrats to accept the demand for reforms. 
An interesting aspect of the optimal program is that the aid trajectory is rising. The reason is simple - improving governance means the bureaucrats can divert less of the aid and so they must be compensated in the form of higher future aid so as not to divert the maximum possible amount, $\alpha\left(g_{1}\right) \mathcal{A}_{1}$, and not fulfill the demand for improvement in governance.

The other point to be noted is that aid diversion happens only in the last period. Offering a bribe early by leaving a slack in period 1 financing is not optimal. Since improvement in governance happens only in period 1, it is better to leave the carrot till the improvement has already taken place so that aid diversion would be minimal. In contrast, in the next section we will see that in a three period problem offering interim bribes is a plausible aid policy.

Let us now write the incentive and financial constraints, (2) and (3), as equalities:

$$
\begin{aligned}
\frac{\alpha\left(g_{2}\right) \mathcal{A}_{2}}{\alpha\left(g_{1}\right)} & =\mathrm{C}\left(g_{2}-g_{1}\right), \\
\mathcal{A}_{1} & =\mathrm{C}\left(g_{2}-g_{1}\right) .
\end{aligned}
$$

From (4), (5) and the budget balancing condition, we have that $\alpha\left(g_{2}\right)\left[A-C\left(g_{2}-g_{1}\right)\right]=$ $\mathrm{C}\left(\mathrm{g}_{2}-\mathrm{g}_{1}\right)$. By totally differentiating this equation and using Assumption 1 , we have the following result.

Proposition 2. The implementable governance level $\tilde{g}_{2}$ is increasing in the overall aid budget, $\mathcal{A}$.

\section{Three Period Horizon: Full Commitment vis-a-vis Time Consistency}

In this section we extend the donor's aid horizon from two periods to three, so that $t=1,2,3$. We examine if the donor would optimally like to spread the aid over more than two periods. Related issues of interest are the time profile of aid and the pattern of reforms - whether the approach should be one of starting with small improvements and growing, or getting the major boost early on and then slowing down. While for $C\left(g^{\prime}-g\right)$ strictly convex (i.e. increasing marginal cost) efficiency considerations may favour a staggered approach, when $\mathrm{C}\left(\mathrm{g}^{\prime}-\mathrm{g}\right)$ is linear this effect is no longer at play. For a significant part of our analysis we are going to assume $\mathrm{C}\left(\mathrm{g}^{\prime}-\mathrm{g}\right)$ to be weakly convex (thus admitting linearity), as in Assumption 1. Also, we will analyze the implications of full and partial commitments with regard to future aid.

- Feasibility, incentive compatibility and some definitions. The donor's objective 
is to maximize $g_{3}$ subject to the various incentive and financial constraints at both $t=1$ and $t=2$. The donor offers a conditional commitment contract whereby the pattern and quantum of per period aid is conditional on the LDC's performance on the governance front. Further, the donor commits to terminating the contract should the recipient fail to deliver on the promise of governance improvement.

[Three Period Aid-governance program] The donor provides an aid of $\mathcal{A}_{1}$ to the LDC at $t=1$, asking it to implement reforms immediately so that the governance level improves to $\mathrm{g}_{2}$ in the next period. At $\mathrm{t}=2$, provided the achieved governance level is at least $g_{2}$ the donor provides a further aid of $\mathcal{A}_{2}$ asking the LDC to improve its governance level to $g_{3}$ in the next period. If the governance level at the end of period 2 is at least $g_{3}$, then the donor provides a further aid of $\mathcal{A}_{3}$ in period 3 . In case the governance level at the end of period $t, t=1,2$, is less than $g_{t+1}$, then the aid program is immediately stopped.

Thus an aid-governance program can be denoted by the profile

$$
\left(\mathcal{A}_{1}, g_{2} ; \mathcal{A}_{2}, g_{3} ; \mathcal{A}_{3}\right)
$$

We next turn to formalizing the various incentive and financial constraints. Given that the whole of the aid amount $\mathcal{A}$ is to be distributed over the three periods, we have

$$
\mathcal{A}_{1}+\mathcal{A}_{2}+\mathcal{A}_{3}=\mathcal{A}
$$

The IC constraint at $t=2$ is given by:

$$
\alpha\left(g_{2}\right)\left[\mathcal{A}_{2}-\mathrm{C}\left(g_{3}-g_{2}\right)\right]+\alpha\left(g_{3}\right) \mathcal{A}_{3} \geq \alpha\left(g_{2}\right) \mathcal{A}_{2}
$$

where the RHS denotes the payoff to the elite if it decides to renege on the contract and appropriate the maximal possible payoff immediately, whereas the LHS is the sum of its payoff at $t=2$ in case it decides to invest in improving governance to $g_{3}$. Simplifying, we obtain

$$
\frac{\alpha\left(g_{3}\right) \mathcal{A}_{3}}{\alpha\left(g_{2}\right)} \geq C\left(g_{3}-g_{2}\right)
$$

The LDC also faces a financial constraint in that the aid available at $t=2$ must be enough to fund the suggested reforms:

$$
\mathcal{A}_{2} \geq \mathrm{C}\left(\mathrm{g}_{3}-\mathrm{g}_{2}\right) \text {. }
$$


Next, the IC constraint at $t=1$ is given by

$$
\alpha\left(g_{1}\right)\left[\mathcal{A}_{1}-\mathrm{C}\left(g_{2}-g_{1}\right)\right]+\alpha\left(g_{2}\right)\left[\mathcal{A}_{2}-\mathrm{C}\left(g_{3}-g_{2}\right)\right]+\alpha\left(g_{3}\right) \mathcal{A}_{3} \geq \alpha\left(g_{1}\right) \mathcal{A}_{1}
$$

Re-organizing, we have

$$
\frac{\alpha\left(g_{2}\right)\left[\mathcal{A}_{2}-\mathrm{C}\left(g_{3}-g_{2}\right)\right]}{\alpha\left(g_{1}\right)}+\frac{\alpha\left(g_{3}\right) \mathcal{A}_{3}}{\alpha\left(g_{1}\right)} \geq C\left(g_{2}-g_{1}\right)
$$

And the financial constraint at $t=1$ is given by

$$
\mathcal{A}_{1} \geq \mathrm{C}\left(\mathrm{g}_{2}-\mathrm{g}_{1}\right)
$$

Definition 2 (Feasibility). Given $\mathrm{g}_{1}$ and the aid budget $\mathcal{A}$, a program $\left(\mathcal{A}_{1}, \mathrm{~g}_{2} ; \mathcal{A}_{2}, \mathrm{~g}_{3} ; \mathcal{A}_{3}\right)$ is feasible if it satisfies the budget, incentive and financial constraints (6)-(10).

We shall focus on two classes of programs, both equally natural depending on the context, with different degrees of commitment on the part of the donor. Under full conditional commitment (henceforth FCC), the donor can commit to the period 2 and period 3 programs at $t=1$ itself. This implies that the aid-governance program under FCC need not be time consistent, in the sense that the optimal program prescribed from $t=2$ onwards need not maximize donor utility standing at $t=2$. We shall also examine a scenario with partial conditional commitment (henceforth PCC), where the donor cannot commit to the program from $t=2$ onwards. What the donor can commit to is that, subject to the governance level being at least $g_{2}$ at $t=2$, it will offer another conditional contract for the remaining two periods, where the total aid budget is going to be $\mathcal{A}-\mathcal{A}_{1}$. Clearly the PCC program involves time consistency.

Whether FCC or PCC is more natural depends on the donor's specific charter, i.e., whether it is capable of making a commitment. If the donor is a durable financial institution such as the World Bank or the IMF, and moreover is not directly answerable to the public, ${ }^{17}$ then FCC would be natural. If, however, the donor is a country's incumbent government, its power to fully plan out the aid sequence may be limited especially if the aid horizon outlasts the government's tenure, in which case requiring time consistency, leading to a PCC program, might be more plausible. In fact if aid is bilateral - from one country to another - the threat of conditional aid with intermittent re-evaluation while asking the recipient country

\footnotetext{
${ }^{17}$ While Kanbur (2000)'s account of how the World Bank caved in to external pressures for not enforcing conditionality clauses when dealing with the African debt shows the difficulty of commitment itself, which is a fundamental problem of making aid work as voiced by Svensson (2003), it also shows that the organizations like the World Bank are perhaps more likely to fit in our FCC model description.
} 
to make the necessary reforms is more credible, as exemplified by the recent discussions in the UK about their aid policies mentioned in the Introduction. After all, the donor country's government is answerable to its electorate.

We next consider these two alternative programs in more detail.

Definition 3 (Optimality under FCC). Given $\mathrm{g}_{1}$ and the aid budget $\mathcal{A}$, an aid-governance program $\left(\mathcal{A}_{1}, \mathrm{~g}_{2} ; \mathcal{A}_{2}, \mathrm{~g}_{3} ; \mathcal{A}_{3}\right)$ is optimal under full conditional commitment if it solves the following problem:

$\max g_{3}$

subject to: feasibility conditions $(6)-(10)$.

Denote the optimal FCC program by $\left(\hat{\mathcal{A}}_{1}, \hat{g}_{2} ; \hat{\mathcal{A}}_{2}, \hat{g}_{3} ; \hat{\mathcal{A}}_{3}\right)$.

Definition 4. An aid-governance program $\left(\mathcal{A}_{1}, \mathrm{~g}_{2} ; \mathcal{A}_{2}, \mathrm{~g}_{3} ; \mathcal{A}_{3}\right)$ is said to be time consistent if $\left(\mathcal{A}_{2}, \mathrm{~g}_{3} ; \mathcal{A}_{3}\right)$ maximizes donor utility starting in period 2 , and a staring aid amount of $\mathcal{A}-\mathcal{A}_{1}$.

We operationalize the notion of time consistency by observing that the donor's problem in period 2 is identical to the two period problem analyzed in section 3. Thus from Proposition 2, time consistency requires that the financial constraint for $t=2$, i.e. (8), will be binding along with the IC at $t=2$, i.e., condition (7). These equations will yield, uniquely, the solutions $g_{3}\left(g_{2}, \mathcal{A}_{1}\right)$ and $\mathcal{A}_{2}\left(g_{2}, \mathcal{A}_{1}\right)$. We are now in a position to define optimality under PCC.

Definition 5 (Optimality under PCC). Given $\mathrm{g}_{1}$ and the aid budget $\mathcal{A}$, an aid-governance program $\left(\mathcal{A}_{1}, \mathrm{~g}_{2} ; \mathcal{A}_{2}, \mathrm{~g}_{3} ; \mathcal{A}_{3}\right)$ is optimal under partial conditional commitment, if it solves the following problem:

$\max g_{3}$

subject to : feasibility constraints (6) - (10), and time consistency.

Denote the optimal PCC program by $\left(\mathcal{A}_{1}^{*}, \mathrm{~g}_{2}^{*} ; \mathcal{A}_{2}^{*}, \mathrm{~g}_{3}^{*} ; \mathcal{A}_{3}^{*}\right)$.

Before proceeding with the formal analysis, let us fix a few concepts that form the principal themes of this paper.

Definition 6 (Gradualism). In the three period problem, an aid-governance scheme $\left(\mathcal{A}_{1}, \mathrm{~g}_{2} ; \mathcal{A}_{2}, \mathrm{~g}_{3} ; \mathcal{A}_{3}\right)$ satisfies gradualism if and only if it involves

1. gradualism in aid, i.e. $\mathcal{A}_{i}>0, i=1,2,3$, and 
2. gradualism in governance, i.e. $\mathrm{g}_{3}>\mathrm{g}_{2}>\mathrm{g}_{1}$.

Definition 7 (Quick fix). An aid-governance plan is a quick-fix if for any target governance improvement $\mathrm{g}$, the authorities adopt a two period approach, i.e. $\mathcal{A}_{3}=0$ and $\mathrm{g}_{2}=\mathrm{g}$.

It may be noted that, in principle, there is nothing to rule out $g_{3}>g_{2}>g_{1}$ with an accompanying aid program of $\mathcal{A}_{1}>0, \mathcal{A}_{2}=0$ and $\mathcal{A}_{3}>0$. Such a scheme must incentivize the recipient to carry on with the improvement of governance from $g_{2}$ to $g_{3}$ even if no interim aid, $\mathcal{A}_{2}>0$, is provided. But for this to happen, the aid recipient must carry forward some $\Delta>0$ surplus fund from period 1 efforts to period 2 activities rather than stealing it. But then the aid authority should be able to understand the incentive, and thus hold back the $\Delta$ amount from $\mathcal{A}_{1}$ to alter second-period aid from $\mathcal{A}_{2}=0$ to $\mathcal{A}_{2}=\Delta$. Our definitions of gradualism in governance improvement and aid gradualism, therefore, go hand-in-hand: one implies the other.

Definition 8 (Starting small). An aid-governance mechanism $\left(\mathcal{A}_{1}, \mathrm{~g}_{2} ; \mathcal{A}_{2}, \mathrm{~g}_{3} ; \mathcal{A}_{3}\right)$ satisfies the "starting small and grow later" principle (henceforth SSGL) if and only if

1. it involves SSGL in aid, i.e. $\mathcal{A}_{1}<\mathcal{A}_{2}<\mathcal{A}_{3}$, and

2. it involves SSGL in governance, i.e. $\mathrm{g}_{3}-\mathrm{g}_{2}>\mathrm{g}_{2}-\mathrm{g}_{1}>0$.

Aid gradualism does not necessarily imply the starting small aid principle. Nor does gradualism in governance improvement imply starting small principle of governance improvement. The starting small principle is thus a stronger form of gradualism.

- Gradualism \& the Aid Structure: The FCC Case. We begin by showing that for the same overall aid, allowing a longer horizon achieves better governance. Further, the improvement is done with definite progress made in each stage rather than in one single push. That is, aid conditioning works more efficiently when the carrot-and-stick has more time to play with, suggesting a patient and gradual approach is a better strategy for aid givers.

Proposition 3 (Virtue of patience). Suppose Assumption 1 holds. Fixing the available aid budget at $\mathcal{A}>0$, the optimal aid program under full commitment will exhibit the following characteristics:

(i) A three period program of governance improvement dominates the quick-fix solution involving only two periods. That is, the final governance level achievable is strictly higher in a three period program. 
(ii) In the three period setup, governance improvement occurs gradually with $\hat{\mathrm{g}}_{3}>\hat{\mathrm{g}}_{2}>\mathrm{g}_{1}$ and $\hat{\mathcal{A}}_{i}>0, i=1,2,3$.

The idea is as follows. Note that in the optimal two period program the aid promised for the final round, $\tilde{\mathcal{A}}_{2}$, does not contribute to governance improvement. With an extended three period horizon, part of this amount $\tilde{\mathcal{A}}_{2}$ can be moved to period 3, conditioning the release of this amount on further reforms in the second period. Intuitively, this generates a trade-off. First, since the aid amount is split up into smaller tranches, the gain from deviating in any one period is smaller. On the other hand, the gain from complying also gets smaller, since, because of governance improvements, aid diversion gets more difficult. However, in the optimal contract the first effect necessarily dominates since the donor can always design the associated reforms in an appropriate fashion. Consequently the reform agenda can be pushed further. Interestingly, this intuition follows purely from the logic of gradualism, and does not require the cost function $\mathrm{C}($.) to be convex.

Formally, one can split the aid amount earmarked for period 2 under the optimal two period program among period 2 and 3 while maintaining the original $g_{2}$ and setting $g_{3}=g_{2}$ (i.e. no real improvement in the final round), because there is no discounting and thus the combined aid diversion opportunity (period 2 and period 3 together) remains the same. With positive aid retained in period $2, \mathrm{~g}_{2}$ can now be lowered slightly (to some $\mathrm{g}_{2}^{\prime}$ ) that is made up for by requiring an equivalent $\mathrm{g}$-improvement in period 3 to maintain $\mathrm{g}_{3}=\mathrm{g}_{2}$. And this is possible without prompting default through maximal aid diversion from the set governance objectives in period 1 or period 2, due to a combination of weak convexity of the cost function $\mathrm{C}($.), decreasing $\alpha(\mathrm{g})$, and interim bribery opportunity in period 2 (see Step 3 of the proof). Finally, as $\mathrm{g}_{2}$ is lowered all of the constraints become slack so that the final $\mathrm{g}$ can be increased at the end of period 3 beyond the original $\mathrm{g}_{2} \cdot{ }^{18}$

As a counterpart to Proposition 3, a relevant question is the implementation of a target level of governance and an appropriate time frame for it. It stands to reason that for any given time frame, two periods or three periods, the higher the aid budget the higher the implementable $\mathrm{g}$, giving rise to an upward-sloping function $\mathrm{g}(\mathcal{A}, \tau), \tau=2,3 .{ }^{19}$ Then Proposition 3 suggests that plotted against the aid budget, the function $g(\mathcal{A}, 3)$ should be placed strictly above $g(\mathcal{A}, 2)$, over the range of $g$-values that are implementable under both time horizons. Combining these two observations (see Fig. 1) leads us to the following result:

\footnotetext{
${ }^{18}$ While the argument relies on "small changes" and thus might appear to be a local analysis, the dominance through gradualism is of a general nature. It only suggests that the dominance is possible without necessarily exploiting the best possible mechanism.

${ }^{19}$ For two periods, this has been verified in Proposition 2. We omit the verification in the three period case.
} 


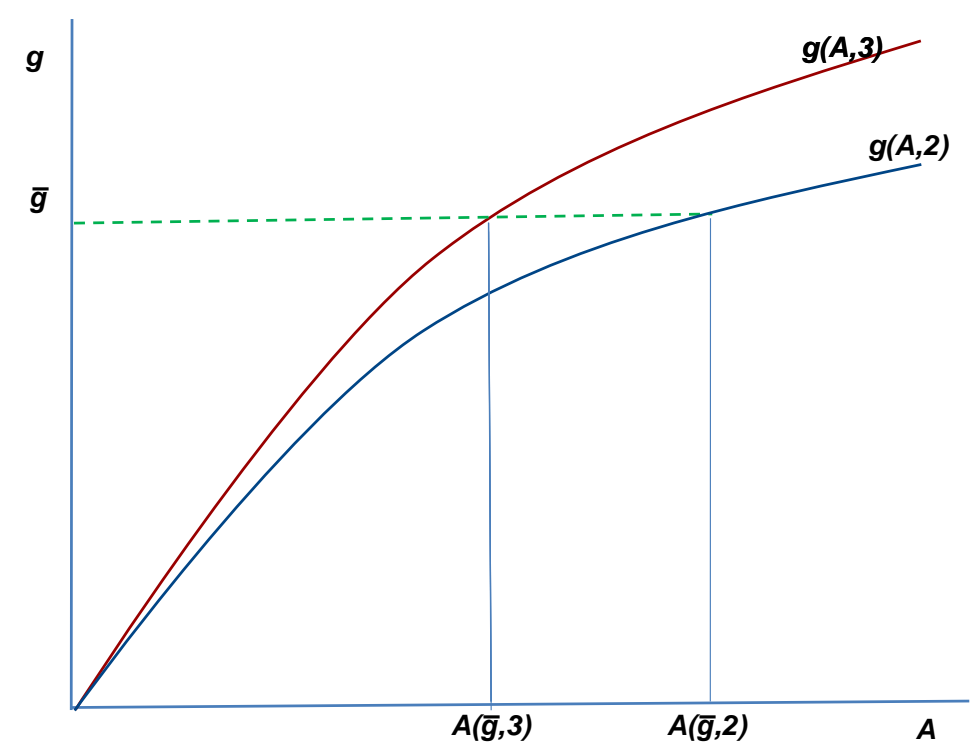

Figure 1: Implementation cost

Proposition 4 (Gradualism: implementation cost). Suppose Assumption 1 holds. Fixing the governance implementation target at some level $\overline{\mathrm{g}}>\mathrm{g}_{1}$, under full commitment the implementation cost, $\mathcal{A}(\overline{\mathrm{g}}, 3)$, is strictly lower with a gradual approach compared to that with a quick-fix solution, $\mathcal{A}(\overline{\mathrm{g}}, 2)$.

Thus from a purely financial point of view, the lower implementation costs may justify aid agencies adopting a measured wait-and-see approach to governance reforms and keeping the recipient country on a tight leash. Further, this result goes through even in the presence of a moderate degree of discounting. These results provide a rationale for tough talks in recent years by the United Kingdom for aid cancellations as a disciplining device. ${ }^{20}$

The next result is technical, suggesting how the various constraints impact on the optimal aid program. Part of the characterization will be used below (in Proposition 6) to determine the optimal time structure of aid.

\footnotetext{
${ }^{20}$ When the donor is a country (such as the UK) rather than a financial institution such as the IMF or the World Bank, the usual pressure of having to fully disburse the allocated funds does not necessarily become an issue, especially when the top level government department from the donor country wants to send a signal to corrupt governments. Thus, credible commitment to conditional aid should be a reasonable working hypothesis.
} 
Proposition 5 (Partial characterization of optimal FCC program). Suppose Assumption 1 holds. With the feasibility requirements (6)-(10), the donor's optimal program can be partlially characterized as follows:

(i) Both period 1 financial constraint, (10), and period 2 incentive constraint, (7), must be binding.

(ii) At least one of the two constraints - period 2 financial constraint, (8), and period 1 incentive compatibility constraint, (9) - must bind.

(iii) If the equilibrium governance improvement program satisfies a weaker version of SSGL, i.e. $\hat{\mathrm{g}}_{3}-\hat{\mathrm{g}}_{2} \geq \hat{\mathrm{g}}_{2}-\mathrm{g}_{1}$, then the constraint (9) would bind.

Intuitively, the period 1 financial constraint binds because, with the aid program starting in period 1, any slack in period 1 cannot be used to incentivize either current or future reforms, and is just a waste of aid money. Similarly, if the incentive constraint in the second period is slack, this means that the aid allocated to the last period, i.e. $\hat{\mathcal{A}}_{3}$, can be reallocated as follows. Let us reduce $\hat{\mathcal{A}}_{3}$ by a small amount (this has no financial implications as there is no reform in period 3), and re-distribute the amount so freed up between $\hat{\mathcal{A}}_{1}$ and $\hat{\mathcal{A}}_{2}$ without affecting the incentive constraint in period 2. This relaxes all the constraints so that the reforms agenda can be pushed further.

Given part (ii), any of three combinations can characterize the optimal aid contract: both (8) and (9) binding; only (8) binding and (9) non-binding; and (8) non-binding and (9) binding. The first possibility yields all constraints binding, and the second possibility keeps default incentives in check with the final round aid diversion, $\alpha\left(g_{3}\right) \mathcal{A}_{3}$, strictly dominating earlier round opportunities. The third possibility offers an interesting policy direction. Here the aid authorities may knowingly tolerate interim aid diversion by recipient country bureaucrats in order to achieve a better governance in the bargain. That is, to put our earlier quote of the UK International Development Secretary Andrew Mitchell's stern warnings in perspective, despite his tough talk it would be wise to also adopt a more pragmatic approach when dealing with corrupt bureaucracies: bribe the bureaucrats to improve governance and thereby, in the long run, reduce corruption. We address this issue in subsection later on.

Proposition 5 is a partial characterization. More structure can be put on the optimal aid scheme under the additional assumption that $\mathrm{C}($.$) is additively separable. Specifically,$ a partial ranking of $\mathcal{A}_{1}, \mathcal{A}_{2}$ and $\mathcal{A}_{3}$ is now possible.

Assumption 2. For any $\mathrm{g}^{\prime}>\mathrm{g}, \mathrm{C}\left(\mathrm{g}^{\prime}-\mathrm{g}\right)=\mathrm{C}\left(\mathrm{g}^{\prime}\right)-\mathrm{C}(\mathrm{g})$.

Assumption 2 allows for linear cost functions so long as we retain Assumption 1 and thus $\mathrm{C}(0)=0$. 
Proposition 6 (Time structure of aid). Suppose both Assumptions 1 and 2 hold.

(i) In the solution of the FCC problem, period 1 incentive compatibility constraint (9) must bind.

(ii) $\alpha\left(g_{1}\right) \hat{\mathcal{A}}_{1}=\alpha\left(\widehat{\mathrm{g}}_{2}\right) \hat{\mathcal{A}}_{2} \geq \alpha\left(\widehat{\mathrm{g}}_{3}\right) \hat{\mathcal{A}}_{3}$ and $\hat{\mathcal{A}}_{1}<\hat{\mathcal{A}}_{2}$.

- Interim Bribery under FCC. We next report an important result on interim bribery. Our result will be based on numerical simulation that is presented in Tables A.1 and A.2 in the Appendix.

Proposition 7. Consider $\mathrm{g}_{1}=0, \alpha(\mathrm{g})=1-\mathrm{g}$ and two alternative assumptions on the cost of governance improvement $\mathrm{C}(\mathrm{x})$ - linear and quadratic.

(i) Consider $\mathrm{c}(\mathrm{x})=\mathrm{x}$. Then, $\forall \mathcal{A} \in[1.4,1.5, \ldots, 2]$, the financial constraint at period 2 is slack. Further, the proportional slack, i.e. $\frac{\hat{\mathcal{A}}_{2}-\left(\hat{\mathrm{g}}_{3}-\hat{\mathrm{g}}_{2}\right)}{\mathcal{A}}$, is increasing in $\mathcal{A}$.

(ii) Consider $\mathrm{c}(\mathrm{x})=\mathrm{x}^{2}$. Then, $\forall \mathcal{A} \in[1.0,1.1, \ldots, 2]$, the financial constraint at period 2 is slack. Further, the proportional slack, i.e. $\frac{\hat{\mathcal{A}}_{2}-\left(\hat{\mathfrak{g}}_{3}-\hat{g}_{2}\right)}{\mathcal{A}}$, is increasing in $\mathcal{A}$.

What could be the economic reason for creating a slack in period 2 financial constraint, (8)? Intuitively, the idea is to incentivize reforms improvement in period 1. With a slack in a period 2, the elite has a greater incentive to stick to the aid scheme in period 1 , since otherwise the aid program is terminated and the elite cannot benefit from this slack. However, why should the donor create a slack in period 2, rather than shifting the amount to period 3? This is because a transfer of $\Delta$ dollar from the final round reward $\mathcal{A}_{3}$ to $\mathcal{A}_{2}$, increases the recipient's second-period margin by $\left[\alpha\left(\mathrm{g}_{2}\right)-\alpha\left(\mathrm{g}_{3}\right)\right] \Delta>0$. This, in turn, will ease the first-period financial constraint (9) because $\alpha\left(g_{2}\right)>\alpha\left(g_{3}\right)$. Given this slack created in the first period financial constraint, the donor can now use the amount so freed up to push up $g_{3}$. This allows the donor to sustain greater reforms overall.

In terms of the difference between the two period problem and the analysis here, now the recipient has to be incentivized in the first round with two more rounds to go, and also in the second round with one last round left. So how the surplus is to be left on the table for bureaucrats, $\left[\mathcal{A}_{2}-\mathrm{C}\left(\mathrm{g}_{3}-\mathrm{g}_{2}\right)\right]$ vs. $\mathcal{A}_{3}$, is an important consideration for balancing incentives. Giving a carrot in the second round could be less costly for first-period incentives as more out of $\left[\mathcal{A}_{2}-\mathrm{C}\left(\mathrm{g}_{3}-\mathrm{g}_{2}\right)\right]$ can be grabbed than from $\mathcal{A}_{3}$. That is, immediate gain to the bureaucrats is more for each dollar expense of the donor than the distant gain. But taking dollars away from $\mathcal{A}_{3}$ also means weaker incentive in the second period to work towards (a higher) $g_{3}$ rather than running away with $\alpha\left(g_{2}\right) \mathcal{A}_{2}$. The optimal program has to 
strike a balance between these two countervailing forces, and may leave an interim surplus $\left[\mathcal{A}_{2}-\mathrm{C}\left(\mathrm{g}_{3}-\mathrm{g}_{2}\right)\right]>0$. In the two period version, there is no interim period and hence no such opportunity of intermediate gain.

Proposition 7 also has implications for the dynamic aid structure. While Proposition 6 earlier shows that $\hat{\mathcal{A}}_{1}<\hat{\mathcal{A}}_{2}$, it is unclear as to how the final round of aid should compare. This ambiguity arises solely because of non-binding (8). When the optimal aid package involves interim bribes, the time profile of aid could be non-monotonic in that $\hat{\mathcal{A}}_{2}$ may exceed $\hat{\mathcal{A}}_{3}$, as in Table A.2 (see the proof of Proposition 7 in the Appendix, in particular the entries coded in red). Thus for $\mathcal{A}=1.6$ to $\mathcal{A}=2$, the governance improvement follows a downward trajectory, $\hat{g}_{3}-\hat{g}_{2}<\hat{g}_{2}-g_{1}$, hence failing $S S G L$. In contrast under time consistency to be studied next, we will see that both the aid and governance improvement will have strictly upward trajectories.

- Gradualism \& the Aid Structure: The PCC Case. Adding renegotiation in the aid contract following each round, subject to satisfactory progress in governance, alters the donor's feasible program since it weakens the donor's hand relative to the full commitment program. As a result, the implementable level of governance can only (weakly) worsen. We first analyze the optimal aid mechanism under time consistency, then compare it with the mechanism under full commitment.

The following result is a summary presentation of Lemma A.1 reported in the Appendix.

Proposition 8 (Characterization). Suppose Assumption 1 holds.

(i) Then in the optimal PCC program both pairs of incentive and financial constraints, (7)-(10), will bind.

(ii) There will be no interim bribery.

Interestingly, and in contrast to the result under FCC, we find that the aid package under PCC does not involve interim bribes. This is so because time consistency requires the aid package to be freshly calculated after round 1 . Since the idea behind interim bribery under FCC is to incentivize reforms in period 1, interim bribery becomes redundant in period 2, and will be dispensed with under PCC. This suggests, for example, that interim bribery is more likely to be used whenever the donor country has a stable government which is likely to outlast the aid horizon, or the department dealing in international aid is independent and can commit to a long term program.

Building on the above characterization and Lemma A.1 we obtain our main result under PCC: 
Proposition 9 (Strong gradualism). Suppose Assumption 1 holds. In the three period PCC problem, the optimal aid mechanism involves gradualism as well as the SSGL principle:

(i) $g_{3}^{*}>g_{2}^{*}>g_{1}$ and $\mathcal{A}_{3}^{*}>\mathcal{A}_{2}^{*}>\mathcal{A}_{1}^{*}>0$.

(ii) $g_{3}^{*}-g_{2}^{*}>g_{2}^{*}-g_{1}>0$.

(iii) The final governance level achievable under a three period setup is higher than under a two period setup.

Note that despite the fact the donor faces greater constraints under PCC because of the time consistency requirement, the three period program continues to prevail over a two period scheme. This confirms the power of aid gradualism to deliver on improvements.

Further, both the aid levels and governance improvements exhibit the SSGL property, or what might be termed as strong gradualism. The principle of "starting small and grow later" for conditional commitment has been previously noted in other applications, for instance, Watson (2002) and Klimenko et al. (2008). Its application in the context of aid conditionality should thus be of interest.

Both these results are especially noteworthy as Assumption 1 imposes no restrictions on the curvature of the governance improvement costs, $\mathrm{C}($.$) . In particular, for linear costs$ and zero discounting, purely efficiency considerations suggest that one should expect equal improvement in governance in each round, showing that this non-stationary trend arises purely from the logic of gradualism.

Recall that SSGL may not obtain under FCC, suggesting that it is time consistency that drives this strong property. SSGL in aid can be understood as follows. That $\mathcal{A}_{3}^{*}>\mathcal{A}_{2}^{*}$ follows due to the reason stated following Proposition 1. Absence of interim bribes under sequential rationality means the recipient must be incentivized entirely through aid diversion in the last period, so how $\alpha\left(g_{1}\right) \mathcal{A}_{1}, \alpha\left(g_{2}\right) \mathcal{A}_{2}$ and $\alpha\left(g_{3}\right) \mathcal{A}_{3}$ compare determines the default decision. To avoid default, aid diversions in intermediate stages must be dominated by one in the final round, and sequential rationality implies $\alpha\left(\mathrm{g}_{2}\right) \mathcal{A}_{2}=\alpha\left(\mathrm{g}_{3}\right) \mathcal{A}_{3}$ (see (4) and (5)). So $\alpha\left(g_{1}\right) \mathcal{A}_{1} \leq \alpha\left(g_{2}\right) \mathcal{A}_{2}$, thus $\mathcal{A}_{2}^{*}>\mathcal{A}_{1}^{*}$ follows. Finally, SSGL in governance is a direct implication of there being no interim bribes under sequential rationality and to $\mathcal{A}_{2}^{*}>\mathcal{A}_{1}^{*}$. Under full commitment, the possibility of interim bribes again causes the SSGL property to fail.

An Example. In this example for the PCC case, we verify that the three period problem dominates the two period problem. Consider $\mathrm{C}(\mathrm{x})=\mathrm{x}$ and $\alpha(\mathrm{g})=1-\mathrm{g}$. Moreover, let $g_{1}=0$. 
We first solve for the two period case. From (4) and (5), and putting $\mathbf{g}_{2}=\tilde{\mathbf{g}}$, we have

$$
\mathrm{L}(\tilde{\mathrm{g}}):=(1-\tilde{\mathrm{g}})(\mathcal{A}-\tilde{\mathrm{g}})=\tilde{\mathrm{g}}
$$

Note that the LHS of (11) is convex, initially decreasing and then increasing in $\tilde{\mathbf{g}}$, with $\mathrm{L}(0)>0$. Thus the solution involves (the negative root is chosen as otherwise $\tilde{g}>1$ ):

$$
\tilde{g}=2+\mathcal{A}-\sqrt{(2+\mathcal{A})^{2}-\mathcal{A}} \text {. }
$$

For the three period case, putting $g_{3}=g^{*}$, we obtain ${ }^{21}$

$$
\left(1-g^{*}\right)\left(\mathcal{A}-g^{*}\right)=\left[1-\left(1-g^{*}\right)\left(\mathcal{A}-g^{*}\right)\right]\left[g^{*}-\left(1-g^{*}\right)\left(\mathcal{A}-g^{*}\right)\right] \text {. }
$$

Comparing (11) and (12), we find that $\mathbf{g}^{*}>\tilde{\mathbf{g}}$. This follows as the LHS of both equations have the same functional form, and the RHS of (12) is less than the RHS of (11).

- Comparing FCC and PCC optimal programs. The difference between full and partial commitment mechanisms could be due to one of two reasons - whether in the FCC program the second-period financial constraint, (8), binds or the first-period incentive compatibility constraint, (9), binds. When either constraint fails to bind, clearly the FCC program will strictly dominate the PCC program; otherwise the two programs yield an identical aid package. Under Assumptions 1 and 2, constraint (9) will bind in the FCC program (Proposition 6), so in this case constraint (8) becomes the only difference. A characterization of when (8) may or may not bind is generally a difficult exercise. But as we have earlier demonstrated in Tables A.1 and A.2, the fact that constraint (8) may be slack has a simple economic explanation: interim bribery as a means of improving governance.

\section{Conclusion}

In this paper the analysis of conditional aid is carried out with respect to a single recipient country, and a donor country that is interested in governance. Several natural follow-ups

${ }^{21}$ Using the incentive and financial constraints of the three period case

$$
\begin{aligned}
\left(1-\mathrm{g}_{3}\right)\left(\mathcal{A}-\mathcal{A}_{1}-\mathcal{A}_{2}\right) & =\left(1-\mathrm{g}_{2}\right)\left(\mathrm{g}_{3}-\mathrm{g}_{2}\right) \\
\mathcal{A}_{2} & =\mathrm{g}_{3}-\mathrm{g}_{2}, \\
\left(1-\mathrm{g}_{3}\right)\left(\mathcal{A}-\mathcal{A}_{1}-\mathcal{A}_{2}\right) & =\mathrm{g}_{2} \\
\mathcal{A}_{1} & =\mathrm{g}_{2} .
\end{aligned}
$$

Substituting for $\mathcal{A}_{1}$ and $\mathcal{A}_{2}$ into (9.E) and simplifying we obtain: $\mathrm{g}_{2}=\left(1-\mathrm{g}_{3}\right)\left(\mathcal{A}-\mathrm{g}_{3}\right)$. Substituting the above into (7.E), and setting $\mathrm{g}_{3}=\mathrm{g}^{*}$, we obtain (12). 
suggest themselves. One would be to allow for competing recipients, thus explicitly bringing in an element of contest. Second, a donor may have goals other than, or in addition to, governance, e.g. developmental/welfare goals. Even more interestingly, when the donor deals with more than one claimant, the donor's objective may differ from one country to another - governance improvement and reform in one, and development objectives such as the eradication of child malnutrition, disease control and the likes in another. But even without such complexities, the single-recipient case poses interesting issues and theoretical subtleties. Our work should be viewed as a necessary first step in understanding and analyzing these more complex issues that arise in a more general multilateral aid setting.

Finally, in this paper we abstracted away from any discounting. Of course, discounting will pull the argument back towards a shorter aid horizon. But learning how gradualism works without discounting, which was our focus, is a necessary step towards understanding the problem of optimal aid structure with discounting. Further, given that the payoffs of both the recipient elite and the donor are continuous in the rate of discount, our argument behind the basic gradualism result should remain qualitatively valid as long as the discount factor is close to 1 .

\section{A Appendix}

Proof of Lemma 1. Suppose that contrary to the claim in part (ii) of this lemma, $\tilde{g}_{2}=g_{1}$. We shall argue that in that case it is possible to construct a feasible aid-governance scheme with a higher level of governance. Fixing $\epsilon_{1}>0, \epsilon_{2}>0$, by the continuity of $C\left(g_{2}-g_{1}\right)$ and $\alpha\left(g_{2}\right)-\alpha\left(g_{1}\right)$ we can choose $g_{2}^{\prime}-g_{1}=\eta>0$ appropriately small such that $0<C(\eta)<\epsilon_{1}$ and $\alpha\left(g_{1}\right)-\alpha\left(g_{2}^{\prime}\right)<\epsilon_{2}$.

Now letting $\mathcal{A}_{1}^{\prime}=\epsilon_{1}, \mathcal{A}_{2}^{\prime}=\mathcal{A}-\epsilon_{1}$, we can write

$$
\frac{\alpha\left(g_{2}^{\prime}\right)}{\alpha\left(g_{1}\right)} \frac{\mathcal{A}-\epsilon_{1}}{\epsilon_{1}}>\left[\frac{\alpha\left(g_{1}\right)-\epsilon_{2}}{\alpha\left(g_{1}\right)}\right]\left[\frac{\mathcal{A}-\epsilon_{1}}{\epsilon_{1}}\right]=\left[1-\frac{\epsilon_{2}}{\alpha\left(g_{1}\right)}\right]\left[\frac{\mathcal{A}-\epsilon_{1}}{\epsilon_{1}}\right]>1
$$

where the last inequality holds whenever $\epsilon_{1}$ and $\epsilon_{2}$ are sufficiently small.

Hence, $\alpha\left(g_{2}^{\prime}\right)\left(\mathcal{A}-\epsilon_{1}\right)>\alpha\left(g_{1}\right) \epsilon_{1}>\alpha\left(g_{1}\right) C\left(g_{2}^{\prime}-g_{1}\right)$, satisfying the incentive compatibility condition (2). Finally, by construction, $\mathcal{A}_{1}^{\prime}>\mathrm{C}(\eta)=\mathrm{C}\left(\mathrm{g}_{2}^{\prime}-\mathrm{g}_{1}\right)$, thus satisfying the financial constraint (3). Thus, we have constructed a feasible aid package $\left(\mathcal{A}_{1}^{\prime}, \mathcal{A}_{2}^{\prime}\right)$ leading to $\mathrm{g}_{2}^{\prime}=$ $g_{1}+\eta$ that dominates the initial level of governance $g_{1}$. A contradiction.

Next given that $\tilde{\mathbf{g}}_{2}>\mathrm{g}_{1}$, from (2) we have that $\tilde{\mathcal{A}}_{2}>0$, and from (3) we have that $\tilde{\mathcal{A}}_{1}>0$ (using the fact that $\mathrm{C}(0)=0$ and $\mathrm{C}($.) is strictly increasing). Q.E.D. 
Proof of Proposition 1. First we claim that in the optimal program either (2) or (3) must hold with equality. If not, it is possible to increase $g_{2}$ slightly and still satisfy the incentive and financial constraints. But this would improve governance at $t=2$, a contradiction.

Next we show that both constraints, (2) and (3), must bind. We do this in two steps.

Step 1. First suppose that (2) binds, while (3) does not. Then construct another program $\left(\mathcal{A}_{1}^{\prime}, \mathcal{A}_{2}^{\prime}\right)$ such that $\mathcal{A}_{1}^{\prime}=\tilde{\mathcal{A}}_{1}-\epsilon$ and $\mathcal{A}_{2}^{\prime}=\tilde{\mathcal{A}}_{2}+\epsilon, \epsilon>0$. Given Lemma 1 , such a program exists for $\epsilon$ small. Moreover, for $\epsilon$ small, both the constraints hold with strict inequality. Thus $\mathrm{g}_{2}$ can be increased slightly.

Step 2. Next suppose that (3) binds, while (2) does not. Then construct another program $\left(\mathcal{A}_{1}^{\prime}, \mathcal{A}_{2}^{\prime}\right)$ such that $\mathcal{A}_{1}^{\prime}=\tilde{\mathcal{A}}_{1}+\epsilon$ and $\mathcal{A}_{2}^{\prime}=\tilde{\mathcal{A}}_{2}-\epsilon, \epsilon>0$. Given Lemma 1 , such a program exists for $\epsilon$ small. Moreover, for $\epsilon$ small, both the constraints hold with strict inequality. Thus $g_{2}$ can be increased slightly.

Parts (i) and (ii) follow from the fact that both the financial and incentive constraints bind in the optimal solution. For a proof of (iii), observe that since both the constraints bind we have:

$$
\frac{\alpha\left(\tilde{g}_{2}\right)}{\alpha\left(g_{1}\right)}=\frac{\tilde{\mathcal{A}}_{1}}{\tilde{\mathcal{A}}_{2}} .
$$

The result now follows as $\tilde{g}_{2}>g_{1}$ (from Lemma 1), and $\alpha(\mathrm{g})$ is strictly decreasing. Q.E.D.

Proof of Proposition 3. (i) The proof relies on the following steps.

Step 1. Starting from any initial $g_{1}$, take the optimal two period incentives $\left(\tilde{\mathcal{A}}_{1}, \tilde{\mathrm{g}}_{2} ; \tilde{\mathcal{A}}_{2}\right)$ where $\left(\tilde{\mathcal{A}}_{1}, \tilde{\mathcal{A}}_{2}\right) \gg 0$ and $\tilde{\mathrm{g}}_{2}>\mathrm{g}_{1}$ and plug these values into the IC and financial constraints for the three period problem. That is, we set $\mathcal{A}_{1}=\tilde{\mathcal{A}}_{1}, \mathcal{A}_{2}=\mathcal{A}-\tilde{\mathcal{A}}_{1}=\tilde{\mathcal{A}}_{2}, \mathcal{A}_{3}=0, \mathrm{~g}_{2}=\mathrm{g}_{3}=\tilde{\mathrm{g}}_{2}$. Now check that all four constraints in the three period problem are satisfied:

$$
\begin{aligned}
& \frac{\alpha\left(g_{3}\right) \mathcal{A}_{3}}{\alpha\left(g_{2}\right)} \geq \mathrm{C}\left(\mathrm{g}_{3}-\mathrm{g}_{2}\right) \\
& \text { i.e., } \left.\quad \mathcal{A}_{3}=0=\mathrm{C}\left(\mathrm{g}_{3}-\mathrm{g}_{2}\right) \quad \text { (by } \mathrm{g}_{3}=\mathrm{g}_{2}, \mathcal{A}_{3}=0\right) \text {; } \\
& \mathcal{A}_{2} \geq \mathrm{C}\left(\mathrm{g}_{3}-\mathrm{g}_{2}\right) \\
& \text { i.e., } \quad \mathcal{A}_{2}>0=\mathrm{C}\left(\mathrm{g}_{3}-\mathrm{g}_{2}\right) \quad\left(\text { by } \mathrm{g}_{3}=\mathrm{g}_{2}, \tilde{\mathcal{A}}_{2}>0 \text {, and } \mathcal{A}_{2}=\tilde{\mathcal{A}}_{2}\right) \text {; } \\
& \text { (9) } \alpha\left(g_{2}\right)\left[\mathcal{A}_{2}-\mathrm{C}\left(g_{3}-g_{2}\right)\right]+\alpha\left(g_{3}\right) \mathcal{A}_{3} \geq \alpha\left(g_{1}\right) C\left(g_{2}-g_{1}\right) \\
& \text { i.e., } \quad \alpha\left(g_{2}\right) \mathcal{A}_{2}=\alpha\left(g_{1}\right) \mathrm{C}\left(g_{2}-g_{1}\right) \quad\left(\text { by } \mathcal{A}_{2}>0, g_{3}=g_{2}, \mathcal{A}_{3}=0\right. \text {, and (4)); } \\
& \left.\mathcal{A}_{1}=\mathrm{C}\left(\mathrm{g}_{2}-\mathrm{g}_{1}\right) \quad \text { (true by }(5)\right) \text {. }
\end{aligned}
$$

Starting from the above inequalities, next we will construct another program with a higher $g_{3}$ where all the inequalities are satisfied. 
Step 2. Reduce $\mathcal{A}_{2}$ by $\in$ to $\mathcal{A}_{2}^{\prime}$, and increase $\mathcal{A}_{3}$ by $\in$ to $\mathcal{A}_{3}^{\prime}$. Thus from the above set of inequalities we can write, for $\epsilon$ small,

$$
\begin{aligned}
\alpha\left(g_{3}\right) \mathcal{A}_{3}^{\prime} & >0=\alpha\left(g_{2}\right) C\left(g_{3}-g_{2}\right) \\
\mathcal{A}_{2}^{\prime} & >0=C\left(g_{3}-g_{2}\right) \\
\alpha\left(g_{2}\right)\left[\mathcal{A}_{2}^{\prime}-\mathrm{C}\left(g_{3}-g_{2}\right)\right]+\alpha\left(g_{3}\right) \mathcal{A}_{3}^{\prime} & =\alpha\left(g_{1}\right) C\left(g_{2}-g_{1}\right) \\
\mathcal{A}_{1} & =\mathrm{C}\left(g_{2}-g_{1}\right) .
\end{aligned}
$$

Step 3. Lower $\mathrm{g}_{2}$ slightly to $\mathrm{g}_{2}^{\prime}$ while maintaining $\mathrm{g}_{3}$ at the original $\mathrm{g}_{2}$-value, to obtain:

$$
\begin{aligned}
\alpha\left(g_{3}\right) \mathcal{A}_{3}^{\prime} & >\alpha\left(g_{2}\right) \mathrm{C}\left(g_{3}-g_{2}^{\prime}\right) \\
\mathcal{A}_{2}^{\prime} & >\mathrm{C}\left(g_{3}-g_{2}^{\prime}\right) \\
\alpha\left(g_{2}^{\prime}\right)\left[\mathcal{A}_{2}^{\prime}-\mathrm{C}\left(g_{3}-g_{2}^{\prime}\right)\right]+\alpha\left(g_{3}\right) \mathcal{A}_{3}^{\prime} & >\alpha\left(g_{1}\right) \mathrm{C}\left(g_{2}^{\prime}-g_{1}\right) \\
\mathcal{A}_{1} & >\mathrm{C}\left(g_{2}^{\prime}-g_{1}\right) .
\end{aligned}
$$

Among the inequalities above, only (9.2) needs a bit more explanation; the remaining inequalities follow from continuity of expressions (on both sides of inequalities) in $\mathrm{g}_{2}$. The inequality (9.2) follows by noting that the partial derivative of

$$
\alpha\left(g_{2}\right)\left[\mathcal{A}_{2}^{\prime}-\mathrm{C}\left(g_{3}-g_{2}\right)\right]+\alpha\left(g_{3}\right) \mathcal{A}_{3}^{\prime}-\alpha\left(g_{1}\right) C\left(g_{2}-g_{1}\right)
$$

with respect to $g_{2}$ is

$$
\begin{aligned}
& \alpha^{\prime}\left(g_{2}\right)\left[\mathcal{A}_{2}^{\prime}-C\left(g_{3}-g_{2}\right)\right]+\alpha\left(g_{2}\right) C^{\prime}\left(g_{3}-g_{2}\right)-\alpha\left(g_{1}\right) C^{\prime}\left(g_{2}-g_{1}\right) \\
= & \alpha^{\prime}\left(g_{2}\right) \mathcal{A}_{2}^{\prime}+\alpha\left(g_{2}\right) C^{\prime}(0)-\left.\alpha\left(g_{1}\right) C^{\prime}\left(g_{2}-g_{1}\right)\right|_{\text {at } g_{3}=g_{2}}<0,
\end{aligned}
$$

since $g_{2}>g_{1}, C(0)=0, C^{\prime \prime}() \geq 0,. \alpha^{\prime}(g)<0 \quad($ Assumption 1$)$.

Step 4. Let us now increase $g_{3}$ slightly to $g_{2}+\epsilon^{\prime}$. Since $\epsilon^{\prime}$ is very small and the expressions on both sides of (7.2)-(10.2) are continuous in $g_{3}$, all the inequalities will continue to be maintained, implying $g_{2}+\epsilon^{\prime}$ is achievable under the three period program, thus proving the claim.

(ii) To establish gradualism first we show that $\hat{\mathrm{g}}_{3}>\hat{\mathrm{g}}_{2}$, then we eliminate the possibility that $\hat{g}_{2}=g_{1}$.

Suppose, to the contrary, $\hat{\mathrm{g}}_{3}=\hat{\mathrm{g}}_{2}$. If $\hat{\mathcal{A}}_{3}=0$, it is a two period program which is not optimal as shown in part (i). So let $\hat{\mathcal{A}}_{3}>0$ and construct an alternative program 
$\left(\mathcal{A}_{1}^{\prime}, \mathrm{g}_{2}^{\prime} ; \mathcal{A}_{2}^{\prime}, \mathrm{g}_{3}^{\prime} ; \mathcal{A}_{3}^{\prime}\right)$ such that

$$
\mathcal{A}_{1}^{\prime}=\mathcal{A}_{1}, \mathcal{A}_{2}^{\prime}=\mathcal{A}_{2}+\mathcal{A}_{3}, \mathcal{A}_{3}^{\prime}=0, \mathrm{~g}_{2}^{\prime}=\mathrm{g}_{2}, \mathrm{~g}_{3}^{\prime}=\mathrm{g}_{3} .
$$

This is clearly feasible (i.e., satisfy (6)-(10)) but effectively a two period program which, by part (i), can be strictly dominated by a three period program. Hence, $\hat{\mathrm{g}}_{3}>\widehat{\mathrm{g}}_{2}$.

Now consider the possibility $\hat{g}_{2}=g_{1}$. If $\hat{\mathcal{A}}_{1}=0$, effectively it is a two period program which, by part (i), cannot be optimal. So let $\hat{\mathcal{A}}_{1}>0$. Now, starting from this one, construct another program $\left(\mathcal{A}_{1}^{\prime}, g_{2}^{\prime} ; \mathcal{A}_{2}^{\prime}, g_{3}^{\prime} ; \mathcal{A}_{3}^{\prime}\right)$ such that

$$
\mathcal{A}_{1}^{\prime}=0, \mathcal{A}_{2}^{\prime}=\hat{\mathcal{A}}_{1}+\hat{\mathcal{A}}_{2}, \mathcal{A}_{3}^{\prime}=\hat{\mathcal{A}}_{3}, \mathrm{~g}_{2}^{\prime}=\hat{\mathrm{g}}_{2}, \mathrm{~g}_{3}^{\prime}=\hat{\mathrm{g}}_{3} .
$$

Again, this is effectively a feasible two period program, which can be strictly dominated by a three period program. Hence it must be that $\hat{g}_{2}>g_{1}$.

We can therefore conclude that the optimal three period program must exhibit gradualism: $\hat{\mathrm{g}}_{3}>\hat{\mathrm{g}}_{2}>\mathrm{g}_{1}$.

Q.E.D.

Proof of Proposition 5. (i) Suppose period 1 financial constraint does not bind, so (10) holds with strict inequality. Then $\mathcal{A}_{1}$ can be reduced slightly, and $\mathcal{A}_{2}$ and $\mathcal{A}_{3}$ can be increased slightly. This relaxes (7), (8) and (9), so that $\mathrm{g}_{3}$ can be increased slightly, given that $\alpha(\mathrm{g})$ and $\mathrm{C}($.$) are continuous functions. This yields a contradiction.$

Suppose period 2 incentive constraint is not binding, so (7) holds with strict inequality. Now take away some $\zeta>0$ from $\hat{\mathcal{A}}_{3}$ such that (7) continues to hold, and add this $\zeta$ to $\hat{\mathcal{A}}_{2}$ such that both (8) and (9) hold with strict inequalities (strict inequality in (9) follows, since $\hat{\mathrm{g}}_{3}>\hat{\mathrm{g}}_{2}$, which in turn follows from Proposition 3, implies $\left.\zeta \alpha\left(\hat{\mathrm{g}}_{2}\right)>\zeta \alpha\left(\hat{\mathrm{g}}_{3}\right)\right)$. Next take away some $\epsilon>0$ from $\hat{\mathcal{A}}_{2}+\zeta$ (where $\epsilon<\zeta$ ) and add this to $\hat{\mathcal{A}}_{1}$ such that conditions (8) and (9) continue to be satisfied (given that both were satisfied with strict inequalities due to $\zeta$ transfer), and condition (10) now holds with strict inequality. As a result, the solutions $\left(\hat{\mathrm{g}}_{3}, \widehat{\mathrm{g}}_{2}\right)$ are unaffected and yet period 1 financial constraint is not binding, contradicting the first part shown above.

(ii) Suppose not, so that both (8) and (9) hold with strict inequality. Then take away a small $\eta>0$ from $\hat{\mathcal{A}}_{2}$ and add it to $\hat{\mathcal{A}}_{1}$ such that (8) and (9) continue to be satisfied and condition (10) holds with strict inequality. Again, the first part of (i) is contradicted.

(iii) Suppose to the contrary that (9) does not bind. Then, given (i) and (ii) in this 
Proposition, the donor's problem can be written as:

$\max g_{3}$, subject to

$$
\begin{array}{rlll}
\mathcal{A}_{3} & = & \frac{\alpha\left(g_{2}\right)}{\alpha\left(g_{3}\right)} \mathrm{C}\left(g_{3}-g_{2}\right), & (7.3) \\
\mathcal{A}_{2} & = & \mathrm{C}\left(\mathrm{g}_{3}-\mathrm{g}_{2}\right), & (8.3) \\
\alpha\left(\mathrm{g}_{1}\right) \mathcal{A}_{1} & < & \alpha\left(\mathrm{g}_{1}\right)\left[\mathcal{A}_{1}-\mathrm{C}\left(\mathrm{g}_{2}-\mathrm{g}_{1}\right)\right]+\alpha\left(\mathrm{g}_{2}\right)\left[\mathcal{A}_{2}-\mathrm{C}\left(\mathrm{g}_{3}-\mathrm{g}_{2}\right)\right]+\alpha\left(\mathrm{g}_{3}\right) \mathcal{A}_{3}, \\
\mathcal{A}_{1} & = & \mathrm{C}\left(\mathrm{g}_{2}-\mathrm{g}_{1}\right) .
\end{array}
$$

Having solved the above problem, below we will return to our (hat) notations for the optimal incentives under the FCC program.

Let us increase $g_{2}$ to $\hat{g}_{2}+\epsilon, \epsilon>0$ small. Then define

$$
Z(\epsilon)=\frac{\alpha\left(\hat{g}_{2}+\epsilon\right)}{\alpha\left(\hat{g}_{3}\right)} C\left(\hat{g}_{3}-\hat{g}_{2}-\epsilon\right)+C\left(\hat{g}_{2}+\epsilon-g_{1}\right)
$$

Thus $\mathrm{Z}($.$) is the sum of the RHS of (7.3) and (10.3), taking the increase in \mathrm{g}_{2}$ into account. Next observe that

$$
\left.Z^{\prime}(0) \equiv Z^{\prime}(\epsilon)\right|_{\epsilon=0}=-\frac{\alpha\left(\hat{g}_{2}\right)}{\alpha\left(\hat{g}_{3}\right)} C^{\prime}\left(\hat{g}_{3}-\hat{g}_{2}\right)+C^{\prime}\left(\hat{g}_{2}-g_{1}\right)+\frac{\alpha^{\prime}\left(\hat{g}_{2}\right)}{\alpha\left(\hat{g}_{3}\right)} C\left(\hat{g}_{3}-\hat{g}_{2}\right)
$$

Given that $C($.$) is strictly increasing and weakly convex, \alpha(g)$ is strictly decreasing (Assumption 1), $\hat{\mathrm{g}}_{3} \geq \hat{\mathrm{g}}_{2}$, and $\hat{\mathrm{g}}_{3}-\hat{\mathrm{g}}_{2} \geq \hat{\mathrm{g}}_{2}-\mathrm{g}_{1}$ (by hypothesis), it follows that

$$
Z^{\prime}(0)<0
$$

Next note that for $\epsilon$ sufficiently small, conditions (7), (8), and (9) will all hold with strict inequality; however, (10) will be violated. ${ }^{22}$ We next argue that $\mathcal{A}_{1}, \mathcal{A}_{2}, \mathcal{A}_{3}$ can be adjusted in such a way that all the required weak inequalities will hold (including equalities).

Let $X^{\prime}, X, Y$ respectively denote the absolute values of the changes in the RHS of (7.3), (8.3), and (10.3) respectively. Given (A.1), for $\epsilon$ small,

$$
X^{\prime}>Y
$$

Next consider $\mathcal{A}_{1}^{\prime}, \mathcal{A}_{2}^{\prime}, \mathcal{A}_{3}^{\prime}$ such that

$$
\mathcal{A}_{1}^{\prime}=\hat{\mathcal{A}}_{1}+\mathrm{Y}, \quad \mathcal{A}_{2}^{\prime}=\hat{\mathcal{A}}_{2} \text {, and } \quad \mathcal{A}_{3}^{\prime}=\hat{\mathcal{A}}_{3}-\mathrm{Y} .
$$

\footnotetext{
${ }^{22}$ Here while we refer to the original feasibility constraints early in section 4 , the reader may as well think in terms of (7.3)-(10.3), for ease of visualization.
} 
Observe that with the above reallocation of the aid budget (from period 3 to period 1), all the inequalities in (7), (8), (9) will continue to hold strictly (as after the $g_{2}$ increase), and now constraint (10) binds. We only need to explain how (9) will hold strictly as the rest are straightforward. The overall change in the LHS of (9.3) is

$$
\begin{array}{cc}
= & -\alpha\left(g_{1}\right)\left[C\left(\hat{g}_{2}+\epsilon-g_{1}\right)-C\left(\hat{g}_{2}-g_{1}\right)\right]+\alpha\left(\hat{g}_{2}+\epsilon\right)\left[\hat{\mathcal{A}}_{2}-C\left(\hat{g}_{3}-\hat{g}_{2}-\epsilon\right)\right] \\
& -\alpha\left(\hat{g}_{2}\right)\left[\hat{\mathcal{A}}_{2}-C\left(\hat{g}_{3}-\hat{g}_{2}\right)\right]-\alpha\left(\hat{g}_{3}\right)\left[C\left(\hat{g}_{2}+\epsilon-g_{1}\right)-C\left(\hat{g}_{2}-g_{1}\right)\right],
\end{array}
$$

which can be kept suitably small due to continuity of the expression in $\epsilon$, to preserve the strict inequality of (9.3). Thus, $g_{3}$ can be increased by a small enough amount to $\hat{g}_{3}+\gamma(\epsilon)$ (i.e., $\gamma(\epsilon)>0$ ) so that all the strict inequalities in (7), (8), (9) continue to hold and (10) binds, which would be a contradiction.

Q.E.D.

Proof of Proposition 6. (i) In the proof of Proposition 5(iii), the key step was to show that $Z^{\prime}(0)<0$. We follow the same method here.

Under Assumption 2, we have

$$
\left.Z^{\prime}(0) \equiv Z^{\prime}(\epsilon)\right|_{\epsilon=0}=C^{\prime}\left(\hat{g}_{2}-g_{1}\right)\left[1-\frac{\alpha\left(\hat{g}_{2}\right)}{\alpha\left(\hat{g}_{3}\right)}\right]+\frac{\alpha^{\prime}\left(\hat{g}_{2}\right)}{\alpha\left(\hat{g}_{3}\right)} C\left(\hat{g}_{3}-\hat{g}_{2}\right)<0,
$$

given that $\hat{\mathrm{g}}_{3}>\hat{\mathrm{g}}_{2}$ (by Proposition 3), $\mathrm{C}($.$) is strictly increasing and \alpha(\mathrm{g})$ is strictly decreasing. The rest of the argument is the same as in Proposition 5(iii).

(ii) We have

$$
\alpha\left(g_{1}\right) \mathrm{C}\left(\hat{g}_{2}-g_{1}\right)=\alpha\left(g_{1}\right) \hat{\mathcal{A}}_{1}=\alpha\left(\hat{g}_{3}\right) \hat{\mathcal{A}}_{3}+\alpha\left(\hat{g}_{2}\right) \hat{\mathcal{A}}_{2}-\alpha\left(\hat{g}_{2}\right) \mathrm{C}\left(\hat{g}_{3}-\hat{g}_{2}\right)=\alpha\left(\hat{g}_{2}\right) \hat{\mathcal{A}}_{2}
$$

where the first equality follows from (10) binding, the second from (9) binding, and the last one from (7) binding. Given that $\hat{\mathrm{g}}_{2}>\hat{\mathrm{g}}_{1}$ (Proposition 3) and $\alpha(\mathrm{g})$ is strictly decreasing, this in turn yields $\hat{\mathcal{A}}_{1}<\hat{\mathcal{A}}_{2}$.

Finally, the claim $\alpha\left(g_{1}\right) \hat{\mathcal{A}}_{1} \geq \alpha\left(\hat{g}_{3}\right) \hat{\mathcal{A}}_{3}$ follows from the second equality above since $\hat{\mathcal{A}}_{2} \geq \mathrm{C}\left(\hat{\mathrm{g}}_{3}-\hat{\mathrm{g}}_{2}\right)$.

Q.E.D.

Proof of Proposition 7. Using Mathematica (see the supplementary file), governance $\mathrm{g}_{3}$ is maximized under the assumption that $\mathrm{g}_{1}=0, \alpha(\mathrm{g})=1-\mathrm{g}$ and two alternative cost (of governance improvement) assumptions - linear $(c(x)=x)$ and quadratic $\left(c(x)=x^{2}\right)$. The results are reported in Tables A.1 and A.2.

As one can see, under the optimal program the constraint (8) in most cases is in slack, i.e. $\hat{\mathcal{A}}_{2}-\mathrm{C}\left(\hat{\mathrm{g}}_{3}-\hat{\mathrm{g}}_{2}\right)>0$. Further, the column $(8) / \mathcal{A}$ indicates that in percentage terms interim 
bribes can be significant, as high as $38 \%$ (refer Table A.2); also, the bribery percentage tends to increase with the aid budget for both Tables.

\begin{tabular}{|c|c|c|c|c|c|c|c|c|c|}
\hline $\mathcal{A}$ & $\hat{\mathcal{A}}_{1}$ & $\widehat{\mathrm{g}}_{2}$ & $\hat{\mathcal{A}}_{2}$ & $\hat{\mathrm{g}}_{3}$ & $\hat{\mathcal{A}}_{3}$ & $\left(6^{\prime}\right)$ & $(7)$ & (8) & $(8) / \mathcal{A}$ \\
\hline 1 & 0.227777 & 0.227777 & 0.294963 & 0.52274 & 0.47726 & 1 & $3.02014 \mathrm{E}-008$ & $3.49962 \mathrm{E}-009$ & - \\
\hline 1.1 & 0.240472 & 0.240472 & 0.316607 & 0.557078 & 0.542922 & 1.09999998825149 & $3.56359317610355 \mathrm{E}-008$ & $9.49248957216042 \mathrm{E}-010$ & - \\
\hline 1.2 & 0.251799 & 0.251799 & 0.336539 & 0.588337 & 0.611663 & 1.2 & 0 & $4.996 \mathrm{E}-016$ & - \\
\hline 1.3 & 0.263458 & 0.263458 & 0.357695 & 0.616717 & 0.678847 & 1.3 & $-5.55112 \mathrm{E}-017$ & 0.00443544 & - \\
\hline 1.4 & 0.289326 & 0.289326 & 0.407116 & 0.642875 & 0.703558 & 1.4 & $-5.55112 \mathrm{E}-017$ & 0.0535668 & $3.82 \%$ \\
\hline 1.5 & 0.313953 & 0.313953 & 0.457626 & 0.667253 & 0.728421 & 1.5 & $9.49517 \mathrm{E}-010$ & 0.104326 & $6.95 \%$ \\
\hline 1.6 & 0.337126 & 0.337126 & 0.508583 & 0.689943 & 0.754291 & 1.6 & $2.45603 \mathrm{E}-008$ & 0.155766 & $\mathbf{9 . 7 3} \%$ \\
\hline 1.7 & 0.359195 & 0.359195 & 0.560537 & 0.711042 & 0.780268 & 1.7 & $-1.11022 \mathrm{E}-016$ & 0.20869 & $12.27 \%$ \\
\hline 1.8 & 0.380132 & 0.380132 & 0.613246 & 0.730642 & 0.806623 & 1.8 & $-1.66533 \mathrm{E}-016$ & 0.262735 & $14.59 \%$ \\
\hline 1.9 & 0.4 & 0.4 & 0.666667 & 0.748837 & 0.833333 & 1.9 & 0 & 0.317829 & $16.72 \%$ \\
\hline 2 & 0.418861 & 0.418861 & 0.720759 & 0.765718 & 0.86038 & 2 & $1.11022 \mathrm{E}-016$ & 0.373903 & $18.69 \%$ \\
\hline
\end{tabular}

\begin{tabular}{ccc}
$\mathcal{A}$ & $(9)$ & $(10)$ \\
\hline 1 & $7.23845 \mathrm{E}-008$ & $-2.17419 \mathrm{E}-010$ \\
1.1 & $7.91897344643022 \mathrm{E}-008$ & $5.84201764741721 \mathrm{E}-009$ \\
1.2 & $-5.55112 \mathrm{E}-017$ & 0 \\
1.3 & $-5.55112 \mathrm{E}-017$ & 0 \\
1.4 & $-5.55112 \mathrm{E}-017$ & 0 \\
1.5 & $5.18476 \mathrm{E}-008$ & $-5.36185 \mathrm{E}-009$ \\
1.6 & $1.51515 \mathrm{E}-008$ & $3.55657 \mathrm{E}-008$ \\
1.7 & $-5.55112 \mathrm{E}-017$ & 0 \\
1.8 & 0 & 0 \\
1.9 & $5.55112 \mathrm{E}-017$ & 0 \\
2 & $5.55112 \mathrm{E}-017$ & 0 \\
\hline
\end{tabular}

Table A.1: Simulation results: $\mathrm{C}(x)=x$

\begin{tabular}{|c|c|c|c|c|c|c|c|c|c|c|c|}
\hline $\mathcal{A}$ & $\hat{\mathcal{A}}_{1}$ & $\hat{\mathrm{g}}_{2}$ & $\hat{\mathcal{A}}_{2}$ & $\hat{\mathrm{g}}_{3}$ & $\hat{\mathcal{A}}_{3}$ & $\left(6^{\prime}\right)$ & $(7)$ & $(8)$ & $(8) / \mathcal{A}$ & $(9)$ & $(10)$ \\
\hline 1 & 0.198828 & 0.445901 & 0.358831 & 0.822418 & 0.442341 & 1 & 0.000000008 & 0.217066 & $21.7 \%$ & $2.57873 \mathrm{E}-008$ & $-3.59719 \mathrm{E}-010$ \\
\hline 1.1 & 0.216793 & 0.46561 & 0.405683 & 0.841707 & 0.477524 & 1.1 & $1.26257 \mathrm{E}-008$ & 0.264234 & $24 \%$ & $2.69114 \mathrm{E}-009$ & $-2.2499 \mathrm{E}-009$ \\
\hline 1.2 & 0.234299 & 0.484045 & 0.454108 & 0.85855 & 0.511593 & 1.2 & $-2.55361 \mathrm{E}-009$ & 0.313854 & $26.15 \%$ & $1.84779 \mathrm{E}-008$ & $3.69984 \mathrm{E}-009$ \\
\hline 1.3 & 0.251265 & 0.501263 & 0.503802 & 0.873313 & 0.544933 & 1.3 & $-3.64195 \mathrm{E}-009$ & 0.365381 & $28.1 \%$ & 0.000000025 & $-5.33398 \mathrm{E}-009$ \\
\hline 1.4 & 0.267717 & 0.517414 & 0.554756 & 0.886296 & 0.577527 & 1.4 & $-2.91145 \mathrm{E}-009$ & 0.418682 & $29.9 \%$ & $2.77482 \mathrm{E}-008$ & $-2.9198 \mathrm{E}-009$ \\
\hline 1.5 & 0.283647 & 0.532585 & 0.606843 & 0.897745 & 0.60951 & 1.5 & 0 & 0.473502 & $31.56 \%$ & 0 & 0 \\
\hline 1.6 & 0.299107 & 0.546907 & 0.660144 & 0.907866 & 0.640749 & 1.6 & $1.43339 \mathrm{E}-008$ & 0.529852 & $33.11 \%$ & $4.2321 \mathrm{E}-008$ & $-7.31378 \mathrm{E}-010$ \\
\hline 1.7 & 0.314246 & 0.560577 & 0.715134 & 0.916836 & 0.670619 & 1.7 & $1.10953 \mathrm{E}-008$ & 0.588214 & $34.6 \%$ & $3.31976 \mathrm{E}-008$ & $-3.71714 \mathrm{E}-010$ \\
\hline 1.8 & 0.328725 & 0.573346 & 0.770472 & 0.9248 & 0.700803 & 1.8 & $-1.49228 \mathrm{E}-009$ & 0.646952 & $35.94 \%$ & $2.85905 \mathrm{E}-008$ & $-8.61455 \mathrm{E}-009$ \\
\hline 1.9 & 0.342547 & 0.585275 & 0.825962 & 0.931886 & 0.731491 & 1.9 & 0.000000023 & 0.705823 & $37.14 \%$ & $7.63415 \mathrm{E}-008$ & $2.23736 \mathrm{E}-007$ \\
\hline 2 & 0.356105 & 0.596745 & 0.883076 & 0.938202 & 0.760819 & 2 & $-2.77556 \mathrm{E}-017$ & 0.766483 & $38.32 \%$ & $5.55112 \mathrm{E}-017$ & 0 \\
\hline
\end{tabular}

Table A.2: Simulation results: $\mathrm{C}(x)=x^{2}$

Remark. The entry, E, refers to exponential function. $\left(6^{\prime}\right)$ is computed for the value of $\hat{\mathcal{A}}_{1}+\hat{\mathcal{A}}_{2}+\hat{\mathcal{A}}_{3}$. (7)-(10) are computed for the surplus values, LHS-RHS of the constraints. Although all surplus values are not exactly zeros, for most cases the values are very close to zeros so that we could take the constraint as "approximately" binding. In particular, there are no inconsistencies between Table A.1 entries showing at several places $\hat{\mathcal{A}}_{1}=\hat{\mathrm{g}}_{2}$ and yet the surplus values in constraint (10) not showing exactly zeros, because both $\hat{\mathcal{A}}_{1}$ and $\hat{g}_{2}$ (just like other choice variables) are approximations that are equal up to a certain number of decimal points. Finally, for the blue colored cells the surplus values are significantly positive, so the constraint (8) can be taken to be slack. Finally, in the Mathematica program we have written the budget constraint as weak inequality, as follows:

$$
\mathcal{A}_{1}+\mathcal{A}_{2}+\mathcal{A}_{3} \leq \mathcal{A}
$$

However, as one can see from Tables A.1 and A.2, in almost all cases the optimal aid profile binds the budget constraint.

Q.E.D. 
Lemma A.1. Suppose Assumption 1 holds. Then the optimal PCC program can be characterized as follows:

(i) Constraints (7), (8), and (10) all bind.

(ii) $\alpha\left(g_{1}\right) \mathcal{A}_{1}^{*} \leq \alpha\left(g_{2}^{*}\right) \mathcal{A}_{2}^{*}=\alpha\left(g_{3}^{*}\right) \mathcal{A}_{3}^{*}$, which implies that $\mathcal{A}_{3}^{*} \geq \mathcal{A}_{2}^{*} \geq \mathcal{A}_{1}^{*}$.

(iii) $g_{3}^{*}-g_{2}^{*} \geq g_{2}^{*}-g_{1}$.

(iv) Period 1 incentive compatibility constraint (9) will bind.

(v) $\mathcal{A}_{1}^{*}>0$.

(vi) $g_{2}^{*}-g_{1}>0$.

Proof. (i) That both (7) and (8) must bind follows from sequential rationality and Proposition 1.

Suppose (10) does not bind, so (10) holds with strict inequality. Then $\mathcal{A}_{1}$ can be reduced slightly, and $\mathcal{A}_{2}$ and $\mathcal{A}_{3}$ can be increased slightly. This relaxes (7), (8) and (9), so that $\mathrm{g}_{3}$ can be increased slightly, given that $\alpha(\mathrm{g})$ and $\mathrm{C}($.$) are continuous functions.$

For the contraposition hypothesis, we also require sequential rationality, so that the contradiction must be established while binding (7) and (8). Now let us increase $g_{3}$ by a small $\epsilon>0$. Then the corresponding change in $\mathcal{A}_{3}$ so as to keep (7) binding is

$$
\alpha\left(g_{3}^{*}\right) d \mathcal{A}_{3}=\alpha\left(g_{2}^{*}\right) C^{\prime}\left(g_{3}^{*}-g_{2}^{*}\right) d g_{3}-\alpha^{\prime}\left(g_{3}^{*}\right) \mathcal{A}_{3}^{*} d g_{3}
$$

Similarly, the change in $\mathcal{A}_{2}$ so as to keep (8) binding is

$$
\mathrm{d} \mathcal{A}_{2}=\mathrm{C}^{\prime}\left(g_{3}^{*}-g_{2}^{*}\right) \mathrm{d} g_{3}
$$

Substituting the above two in (9) the LHS becomes

$$
\begin{aligned}
& =\frac{\alpha\left(g_{2}^{*}\right)}{\alpha\left(g_{1}\right)}\left[C^{\prime}\left(g_{3}^{*}-g_{2}^{*}\right) d g_{3}-C^{\prime}\left(g_{3}^{*}-g_{2}^{*}\right) d g_{3}\right]+\frac{1}{\alpha\left(g_{1}\right)}\left[\alpha\left(g_{3}^{*}\right) d \mathcal{A}_{3}+\alpha^{\prime}\left(g_{3}^{*}\right) \mathcal{A}_{3}^{*} d g_{3}\right] \\
& =\frac{\alpha\left(g_{2}^{*}\right)}{\alpha\left(g_{1}\right)} C^{\prime}\left(g_{3}^{*}-g_{2}^{*}\right) d g_{3}>0,
\end{aligned}
$$

thus satisfying the constraint. The contradiction is finally established.

(ii) Part (i) together with the IC condition (9) imply that $\alpha\left(g_{1}\right) \mathcal{A}_{1}^{*} \leq \alpha\left(g_{3}^{*}\right) \mathcal{A}_{3}^{*}=$ $\alpha\left(g_{2}^{*}\right) \mathcal{A}_{2}^{*}$. The ranking of $\mathcal{A}_{\mathrm{i}}^{*}$ 's follows from the fact that $\alpha\left(\mathrm{g}_{1}\right) \geq \alpha\left(\mathrm{g}_{2}^{*}\right) \geq \alpha\left(\mathrm{g}_{3}^{*}\right)$. 
(iii) Follows from the previous steps, applying that $\mathrm{C}\left(\right.$.) is strictly increasing: $\mathrm{C}\left(\mathrm{g}_{3}^{*}-\right.$ $\left.\mathrm{g}_{2}^{*}\right)=\mathcal{A}_{2}^{*} \geq \mathcal{A}_{1}^{*}=\mathrm{C}\left(\mathrm{g}_{2}^{*}-\mathrm{g}_{1}\right)$.

(iv) Suppose to the contrary that (9) does not bind. Then, given part (i), the donor's problem can be written as:

$\max g_{3}$, subject to

$$
\begin{aligned}
\mathcal{A}_{3} & =\frac{\alpha\left(\mathrm{g}_{2}\right)}{\alpha\left(\mathrm{g}_{3}\right)} \mathrm{C}\left(\mathrm{g}_{3}-\mathrm{g}_{2}\right), \\
\mathcal{A}_{2} & =\mathrm{C}\left(\mathrm{g}_{3}-\mathrm{g}_{2}\right), \\
\alpha\left(\mathrm{g}_{1}\right) \mathcal{A}_{1} & <\alpha\left(\mathrm{g}_{1}\right)\left[\mathcal{A}_{1}-\mathrm{C}\left(\mathrm{g}_{2}-\mathrm{g}_{1}\right)\right]+\alpha\left(\mathrm{g}_{2}\right)\left[\mathcal{A}_{2}-\mathrm{C}\left(\mathrm{g}_{3}-\mathrm{g}_{2}\right)\right]+\alpha\left(\mathrm{g}_{3}\right) \mathcal{A}_{3}, \\
\mathcal{A}_{1} & =\mathrm{C}\left(\mathrm{g}_{2}-\mathrm{g}_{1}\right) .
\end{aligned}
$$

Having solved the above problem, below we will return to our (star) notations for the optimal incentives under the PCC program.

Let us increase $g_{2}$ to $g_{2}^{*}+\epsilon, \epsilon>0$ small. Then define

$$
Z(\epsilon)=\frac{\alpha\left(g_{2}^{*}+\epsilon\right)}{\alpha\left(g_{3}^{*}\right)} C\left(g_{3}^{*}-g_{2}^{*}-\epsilon\right)+C\left(g_{2}^{*}+\epsilon-g_{1}\right) .
$$

Thus $\mathrm{Z}($.$) is the sum of the RHS of (7.3) and (10.3), taking the increase in \mathrm{g}_{2}$ into account. Next observe that

$$
\left.Z^{\prime}(0) \equiv Z^{\prime}(\epsilon)\right|_{\epsilon=0}=-\frac{\alpha\left(g_{2}^{*}\right)}{\alpha\left(g_{3}^{*}\right)} C^{\prime}\left(g_{3}^{*}-g_{2}^{*}\right)+\frac{\alpha^{\prime}\left(g_{2}^{*}\right)}{\alpha\left(g_{3}^{*}\right)} C\left(g_{3}^{*}-g_{2}^{*}\right)+C^{\prime}\left(g_{2}^{*}-g_{1}\right) .
$$

Given that $\mathrm{C}($.$) is strictly increasing and weakly convex, \alpha(\mathrm{g})$ is strictly decreasing (Assumption 1 ), $g_{3}^{*} \geq g_{2}^{*}$, and $g_{3}^{*}-g_{2}^{*} \geq g_{2}^{*}-g_{1}$ (by part (iii) above), it follows that

$$
Z^{\prime}(0)<0
$$

Next note that for $\epsilon$ sufficiently small, conditions (7), (8), and (9) will all hold with strict inequality; however, (10) will be violated. ${ }^{23}$ We next argue that $\mathcal{A}_{1}, \mathcal{A}_{2}, \mathcal{A}_{3}$ can be adjusted in such a way that all the required weak inequalities will hold (including equalities).

Let $X^{\prime}, X, Y$ respectively denote the absolute values of the changes in the RHS of (7.3), (8.3), and (10.3) respectively. Given (A.2), for $\epsilon$ small,

$$
X^{\prime}>Y \text {. }
$$

\footnotetext{
${ }^{23}$ Here while we refer to the original feasibility constraints early in section 4 , the reader may as well think in terms of (7.3)-(10.3), for ease of visualization.
} 
Next consider $\mathcal{A}_{1}^{\prime}, \mathcal{A}_{2}^{\prime}, \mathcal{A}_{3}^{\prime}$ such that

$$
\mathcal{A}_{1}^{\prime}=\mathcal{A}_{1}^{*}+\mathrm{Y}, \quad \mathcal{A}_{2}^{\prime}=\mathcal{A}_{2}^{*}, \quad \text { and } \quad \mathcal{A}_{3}^{\prime}=\mathcal{A}_{3}^{*}-\mathrm{Y} \text {. }
$$

Observe that with the above reallocation of the aid budget (from period 3 to period 1), all the inequalities in (7), (8), (9) will continue to hold strictly (as after the $\mathbf{g}_{2}$ increase), and now constraint (10) binds. $^{24}$ We only need to explain how (9) will hold strictly as the rest are straightforward. The overall change in the LHS of (9.3) is

$$
\begin{aligned}
= & -\alpha\left(g_{1}\right)\left[C\left(g_{2}^{*}+\epsilon-g_{1}\right)-C\left(g_{2}^{*}-g_{1}\right)\right]+\alpha\left(g_{2}^{*}+\epsilon\right)\left[\mathcal{A}_{2}^{*}-C\left(g_{3}^{*}-g_{2}^{*}-\epsilon\right)\right] \\
& -\alpha\left(g_{2}^{*}\right)\left[\mathcal{A}_{2}^{*}-C\left(g_{3}^{*}-g_{2}^{*}\right)\right]-\alpha\left(g_{3}^{*}\right)\left[C\left(g_{2}^{*}+\epsilon-g_{1}\right)-C\left(g_{2}^{*}-g_{1}\right)\right],
\end{aligned}
$$

which can be kept suitably small due to continuity of the expression in $\epsilon$, to preserve the strict inequality of (9.3). Thus, $g_{3}$ can be increased by a small enough amount to $g_{3}^{*}+\gamma(\epsilon)$ (i.e., $\gamma(\epsilon)>0$ ) so that all the strict inequalities in (7), (8), (9) continue to hold and (10) binds, which would be a contradiction.

Given that we require sequential rationality, we need to be slightly more careful as adjusted $\mathcal{A}_{2}^{\prime}$ and $\mathcal{A}_{3}^{\prime}$ above do not bind (7) and (8).

First note that $\lim _{\epsilon \rightarrow 0} \gamma(\epsilon)=0$. Starting from the PCC deviation program $\left(\mathcal{A}_{1}^{\prime}, \mathcal{A}_{2}^{\prime}, \mathcal{A}_{3}^{\prime}, \mathrm{g}_{2}^{*}+\right.$ $\epsilon, g_{3}^{*}+\gamma(\epsilon)$ ), we will now construct another program with (7) and (8) holding with equality and a final governance level higher than $g_{3}^{*}$.

For any $\epsilon>0$, consider $\delta(\epsilon)>0$ and $\beta(\epsilon)>0$ such that $(7)$ and (8) are satisfied with equality:

$$
\begin{aligned}
\frac{\alpha\left(\mathrm{g}_{3}^{*}+\gamma(\epsilon)\right)}{\alpha\left(\mathrm{g}_{2}^{*}+\epsilon\right)}\left(\mathcal{A}_{3}^{\prime}-\delta(\epsilon)\right) & =\mathrm{C}\left(\mathrm{g}_{3}^{*}+\gamma(\epsilon)-\mathrm{g}_{2}^{*}-\epsilon\right), \\
\mathcal{A}_{2}^{\prime}-\beta(\epsilon) & =\mathrm{C}\left(\mathrm{g}_{3}^{*}+\gamma(\epsilon)-\mathrm{g}_{2}^{*}-\epsilon\right) .
\end{aligned}
$$

Since

$$
\lim _{\epsilon \rightarrow 0} \beta(\epsilon)=0=\lim _{\epsilon \rightarrow 0} \delta(\epsilon)
$$

(because in the limit we should get back (7.3) and (8.3), along with $\lim _{\epsilon \rightarrow 0} \gamma(\epsilon)=0$ ), for some $\bar{\epsilon}>0$ small enough the following must be true

$$
\begin{aligned}
& \alpha\left(g_{2}^{*}+\bar{\epsilon}\right)\left(\mathcal{A}_{2}^{\prime}-\beta(\bar{\epsilon})-C\left(g_{3}^{*}+\gamma(\bar{\epsilon})-g_{2}^{*}-\bar{\epsilon}\right)+\alpha\left(g_{3}^{*}+\gamma(\bar{\epsilon})\right)\left(\mathcal{A}_{3}^{\prime}-\delta(\bar{\epsilon})\right)\right. \\
& \geq \alpha\left(g_{1}\right) C\left(g_{2}^{*}+\bar{\epsilon}-g_{1}\right),
\end{aligned}
$$

\footnotetext{
${ }^{24}$ Verification that (10) binds would be as follows: $\mathcal{A}_{1}^{\prime}=\mathcal{A}_{1}^{*}+\mathrm{Y}=\mathcal{A}_{1}^{*}+\mathrm{C}\left(\mathrm{g}_{2}^{*}+\epsilon-\mathrm{g}_{1}\right)-\mathrm{C}\left(\mathrm{g}_{2}^{*}-\mathrm{g}_{1}\right)=$ $C\left(g_{2}^{*}+\epsilon-g_{1}\right)$.
} 
because otherwise we will have contradicted (9) using continuity of both sides of the above inequality (in $\epsilon$ ).

This last inequality (satisfying (9)), for the revised program

$$
\left(\mathcal{A}_{1}^{\prime}+\delta(\bar{\epsilon})+\beta(\bar{\epsilon}), \mathcal{A}_{2}^{\prime}-\beta(\bar{\epsilon}), \mathcal{A}_{3}^{\prime}-\delta(\bar{\epsilon}), g_{2}^{*}+\bar{\epsilon}, g_{3}^{*}+\gamma(\bar{\epsilon})\right)
$$

establishes that the overall governance level is improved to $g_{3}^{*}+\gamma(\bar{\epsilon})$ while satisfying time consistency - a contradiction. Note that while arriving at the contraction constraint (10) remains slack: $\mathcal{A}_{1}^{\prime}+\delta(\bar{\epsilon})+\beta(\bar{\epsilon})>C\left(g_{2}^{*}+\bar{\epsilon}-g_{1}\right)$; time consistency (or sequential rationality) requires only (7) and (8) to bind. ${ }^{25}$ This completes the argument.

(v) Suppose not so that $\mathcal{A}_{1}^{*}=0$. This implies $\mathbf{g}_{2}^{*}=g_{1}$ since (10) is binding. So, (9) can be re-written after using (10) as:

$$
\alpha\left(g_{3}^{*}\right) \mathcal{A}_{3}^{*} \geq 0
$$

Clearly, $\mathcal{A}_{3}^{*}>0$, otherwise the program reduces to an one-shot one. Thus, under the contraposition hypothesis (9) can be written as

$$
\alpha\left(g_{3}^{*}\right) \mathcal{A}_{3}^{*}>0
$$

assuming $\alpha(\mathrm{g})>0, \forall \mathbf{g}$. That is, (9) is non-binding. But this contradicts the result in part (iv).

(vi) Follows from part (v) and the fact that (10) is binding as shown in part (i). Q.E.D.

Proof of Proposition 9. (i) From Lemma A.1, $0<\alpha\left(g_{1}\right) \mathcal{A}_{1}^{*} \leq \alpha\left(g_{2}^{*}\right) \mathcal{A}_{2}^{*}=\alpha\left(g_{3}^{*}\right) \mathcal{A}_{3}^{*}$. It must therefore be that $\mathcal{A}_{1}^{*}, \mathcal{A}_{2}^{*}, \mathcal{A}_{3}^{*} \gg 0$. And since $\mathcal{A}_{1}^{*}=\mathrm{C}\left(\mathrm{g}_{2}^{*}-\mathrm{g}_{1}\right)$ and $\mathcal{A}_{2}^{*}=\mathrm{C}\left(\mathrm{g}_{3}^{*}-\mathrm{g}_{2}^{*}\right)$, it follows that $\mathrm{g}_{3}^{*}>\mathrm{g}_{2}^{*}>\mathrm{g}_{1}$ (apply the fact that $\mathrm{C}(0)=0$ and $\mathrm{C}$ (.) is strictly increasing). Given that $\alpha\left(g_{1}\right) \mathcal{A}_{1}^{*} \leq \alpha\left(g_{2}^{*}\right) \mathcal{A}_{2}^{*}=\alpha\left(g_{3}^{*}\right) \mathcal{A}_{3}^{*}$, this in turn implies that $\mathcal{A}_{3}^{*}>\mathcal{A}_{2}^{*}>\mathcal{A}_{1}^{*}$.

(ii) The result follows from $\mathcal{A}_{2}^{*}=\mathrm{C}\left(\mathrm{g}_{3}^{*}-\mathrm{g}_{2}^{*}\right)>\mathcal{A}_{1}^{*}=\mathrm{C}\left(\mathrm{g}_{2}^{*}-\mathrm{g}_{1}\right)$ and the result above that $\mathcal{A}_{2}^{*}>\mathcal{A}_{1}^{*}>0$, given that $\mathrm{C}($.) is strictly increasing.

(iii) Suppose not so that $\tilde{\mathbf{g}}_{2} \geq \mathrm{g}_{3}^{*}$, where $\tilde{\mathrm{g}}_{2}$ is the maximal implementable $\mathrm{g}$ in the two period setup. Now consider the following three period program: $\left(\mathcal{A}_{1}=0, g_{2}=g_{1} ; \mathcal{A}_{2}=\right.$ $\left.\tilde{\mathcal{A}}_{1}, \mathrm{~g}_{3}=\tilde{\mathrm{g}}_{2} ; \mathcal{A}_{3}=\tilde{\mathcal{A}}_{2}\right)$, where $\left(\tilde{\mathcal{A}}_{1}, \tilde{\mathrm{g}}_{2} ; \tilde{\mathcal{A}}_{2}\right)$ is the optimal two period program. Given the initial governance level $g_{1}$ and first-period aid and target governance $\left(\mathcal{A}_{1}=0, g_{2}=g_{1}\right)$, clearly $\left(\mathcal{A}_{2}=\tilde{\mathcal{A}}_{1}, \mathrm{~g}_{3}=\tilde{\mathrm{g}}_{2} ; \mathcal{A}_{3}=\tilde{\mathcal{A}}_{2}\right)$ is time consistent in the subgame starting in period 2. Stepping back to period 1 it is easy to see that the three period program $\left(\mathcal{A}_{1}=0, g_{2}=\right.$

\footnotetext{
${ }^{25}$ That constraint (10) should bind is a requirement of the optimal PCC program as shown in part (i) above, but not for sequential rationality.
} 
$\left.\mathrm{g}_{1} ; \mathcal{A}_{2}=\tilde{\mathcal{A}}_{1}, \mathrm{~g}_{3}=\tilde{\mathrm{g}}_{2} ; \mathcal{A}_{3}=\tilde{\mathcal{A}}_{2}\right)$ is feasible as per Definition 2. But then it cannot be optimal in the three period program as it fails to satisfy the optimality requirement $g_{3}^{*}>g_{2}^{*}>g_{1}$ as shown in part (i). This contradicts our hypothesis that $g_{3}^{*} \leq \tilde{g}_{2}$.

Q.E.D.

\section{References}

Bag, P.K. and P. Roy Chowdhury, "Gradualism in aid and development," Working paper 2014.

Bakoup, F., "Promoting economic reform in developing countries: Rethinking budgetary aid?," Working paper no. 167, African Development Bank Group (http://www.afdb.org/en/news-and-events/article/country-economic-thematic-review-meetingpromoting-economic-reforms-in-developing-countries-rethinking-budgetary-aid-11554/), 2013.

Banerjee, A.V., "Making aid work: How to fight global poverty effectively," in Making Aid Work, Boston Review/MIT Press (also available at http://iisdb.stanford.edu/evnts/4741/MakingAidWork.pdf), 2007.

_ and R. He, "Making aid work," in W. Easterly (Ed.), Reinventing foreign aid, MIT Press, Cambridge, Massachusetts, 2008, pp. 44-92.

Bond, E.W. and J.H. Park, "Gradualism in trade agreements with asymmetric countries," Review of Economic Studies, 2002, 59, 367-397.

Boone, P., "Politics and the effectiveness of foreign aid," European Economic Review, 1996, 40, 289-329.

Bourguignon, F. and M. Sundberg, "Aid effectiveness: Opening the blackbox," American Economic Review Papers and Proceedings, 2007, 97, 316-321.

Burnside, C. and D. Dollar, "Aid, policies and growth," American Economic Review, 2000, 90, 847-868.

Carter, P., F. Postel-Vinay, and J. Temple, "Dynamic aid allocation," Journal of International Economics, 2015, 95, 291-304.

Chisik, R., "Gradualism in free trade agreements: a theoretical justification," Journal of International Economics, 2003, 59, 367-397. 
Conway, P., "Endogenous IMF conditionality: Theoretical and empirical implications," Department of Economics, University of North Carolina, Working paper, http://www.unc.edu/ p conway/dload/ec_conway.pdf 2003.

Easterly, W., "Can foreign aid buy growth," Journal of Economic Perspectives, 2003, 17, $23-48$.

EC, "Communication from the Commission to the European Parliament, the Council, the European Economic and Social Committee of the Regions: The Future Approach to the EU Budget Support to Third Countries. Brussels, 13.10.2011 COM(2011) 638 final," European Commission 2011.

Kanbur, R., "Aid conditionality and debt in Africa," in Finn Tarp (Ed.), Foreign aid and development: Lessons learnt and directions for the future, Routledge Press, 2000.

Kapur, D. and R. Webb, "Governance-related conditionalities of the International Financial Institutions," New York and Geneva: United Nations Conference on Trade and Development, G-24 Discussion Paper Series 6, https://ideas.repec.org/p/unc/g24pap/6.html 2000.

Kaufmann, D., A. Kraay, and P. Zoido-Lobaton, "Governance matters," Policy Research Working Paper 2196, The World Bank, http://papers.ssrn.com/sol3/papers.cfm?abstract_id=188568 1999.

Klimenko, M., G. Ramey, and J. Watson, "Recurrent trade agreements and the value of external enforcement," Journal of International Economics, 2008, 74, 475-489.

Lockwood, B. and J.P. Thomas, "Gradualism and irreversibility," Review of Economic Studies, 2002, 69, 339-356.

Marx, L. and S. Matthews, "Dynamic voluntary contributions to a public project," Review of Economic Studies, 1998, 67, 327-358.

Neher, D.V., "Staged financing: An agency perspective," Review of Economic Studies, 1999, 66, 255-274.

Santiso, C., "Good governance and aid effectiveness: The World Bank and conditionality," The Georgetown Public Policy Review, 2001a, 7, 1-22.

_ , "International co-operation for democracy and good governance: Moving toward a second generation?," European Journal of Development Research, 2001b, 13, 154-180. 
Staiger, R.W., "A theory of gradual trade liberalization," In J. Levinsohn, A.V. Deardorff and R.M. Stern (Eds.), New Directions in Trade Theory, University of Michigan Press Ann Arbor, MI, 1995.

Svensson, J., "Aid, growth, and democracy," Economics and Politics, 1999, 11, 275-297.

_., "Foreign aid and rent seeking," Journal of International Economics, 2000a, 51, 437-461.

_. "When is foreign aid policy credible? Aid dependence and conditionality," Journal of Development Economics, 2000b, 61, 61-84.

_ , "Why conditional aid does not work and what can be done about it?," Journal of Development Economics, 2003, 70, 381-402.

Temple, J.R.W., "Aid and conditionality," in D. Rodrick and M. Rosenzweig (Eds.), Handbook of Development Economics, 2010, 5, 4415-4518.

Watson, J., "Starting small and commitment," Games and Economic Behavior, 2002, 38, 176-199. 